Federal Reserve Bank of Minneapolis

Research Department Working Paper 718

Revised September 2015

\title{
On the Stability of Money Demand*
}

\author{
Robert E. Lucas Jr. \\ University of Chicago \\ Juan Pablo Nicolini \\ Federal Reserve Bank of Minneapolis \\ and Universidad Di Tella
}

\begin{abstract}
We show that regulatory changes that occurred in the banking sector in the early eighties, that considerably weakened Regulation Q, can explain the apparent instabilty of money demand starting in the same period. We evaluate the effects of the regulatory changes using a model that goes beyond aggregates as M1 and treats currency and different deposit types as alternative means of payments. We use the model to construct a new monetary aggregate that performs remarkably well for all the period 1915-2012.
\end{abstract}

Keywords: Money demand; Monetary base

JEL classification: E40, E41

\footnotetext{
*This paper was presented at the November 2014 Carnegie Rochester NYU Conference on Public Policy. We thank Fernando Alvarez, Uberto Ennis, Peter Ireland, Finn Kydland, Ricardo Lagos, Francesco Lippi, Andy Neumeyer, Fabrizio Perri, Nancy Stokey, Pedro Teles and Randy Wright for helpful discussions and Joao Ayres, Manuel Macera and Serginio Sylvain for outstanding assistance. The views expressed herein are those of the authors and not necessarily those of the Federal Reserve Bank of Minneapolis or the Federal Reserve System.
} 


\section{INTRODUCTION}

The failure of Lehman Brothers in September, 2008 immediately led to a severe banking panic, a rush by banks to exchange privately issued cash substitutes for government issued or government guaranteed cash. The Federal Reserve responded to this situation by increasing the level of bank reserves from some $\$ 40$ billion on September 1 to $\$ 800$ b. by New Years Day. This single action was surely the main factor in the resolution of the liquidity crisis by early 2009 and the ending of the decline in production after two quarters.

It is a remarkable feature of these events that none of the leading macroeconometric models - including the model in use by the Fed itself- had anything to contribute to the analysis of this liquidity crisis or of the Fed's response to it. None of these models had any role for bank reserves or for any other monetary aggregate or measure of liquidity. Central bankers, as always, used short interest rates as the only indicator of the stance of monetary policy but sometime in the 1990s they were joined by most influential monetary economists. A broad consensus was reached that no measure of "liquidity" in an economy was of any value in conducting monetary policy.

There were understandable reasons behind this consensus. Long standing empirical relations connecting monetary aggregates like M1, M2 and the monetary base to movements in prices and interest rates began to deteriorate in the 1980s and have not been restored since, as we document in Section 2. One objective in this paper is to offer a diagnosis of this empirical breakdown. A second is to propose a fix, to construct a new monetary aggregate that offers a unified treatment of monetary facts preceding and following $1980 .^{1}$

To do this we need to get behind such broad aggregates as M1 and M2 and model

\footnotetext{
${ }^{1}$ Several economists have offered useful diagnoses of the behavior of M1 and M2 since 1980 and proposed other monetary measures. These include Broaddus and Goodfriend (1984), Motley (1988), Poole (1991), Reynard (2004), Teles and Zhou (2005) and Ireland (2009).
} 
the role of currency and different kinds of deposits in the payment system in an explicit way. For this purpose we adapt the model of Freeman and Kydland (2000) (based on earlier work by Prescott (1987)) to consider the distinct roles of currency, reserves, and commercial bank deposits. This model proposes a banking "technology" that rationalizes the adding-up of different assets to form aggregates like M1, and does so with some realism. It treats currency and demand deposits as distinct assets and can readily be adapted to include other forms of liquidity. This is what we do in Section 3, where we introduce another monetary asset, money market deposit accounts (MMDAs), as a third important means of payment along side currency and demand deposits. The model rationalizes our use of a new, single monetary aggregate - we call it NewM1 - that coincides with M1 prior to 1982 and includes the newly created MMDAs for the years since. In this section we treat banking activities as though they were conducted within each household, in order to situate banking activities within a general equilibrium framework. We decentralize the model in Section 4, obtaining a model of competitive banking firms.

In Section 5, we calibrate the model and compare its implications to U.S data for the free interest rates period (1915-1935 and 1983-2012). We show the model matches the behavior of the aggregate NewM1 remarkably well for the entire period. We also show that the model can reproduce some - but not all — of the features exhibited by the components of NewM1 in the data.

In the model described and applied in Sections 3-5, banking is treated as a freeentry, competitive industry, where banks are free to charge market interest rates on deposits. Of course, this description has never been literally accurate. In fact, among the provisions of the 1933 Glass-Steagall Act was the explicit prohibition-Regulation Q - of interest payments on bank deposits. In Section 6 we modify the basic model to provide an analysis of a banking system distorted by Regulation Q. We use this modified model to analyze the period with restricted interest rates (1936-1982) and 
discuss the important effects of Regulation Q on the U.S. financial system during the inflation of the 1970s and 80s. The model captures some - but not all - of the features of the Regulation Q period. Section 7 contains concluding remarks.

\section{THE BEHAVIOR OF MONEY DEMAND}

Figure 1. $a$ plots the ratio of M1 to GDP for the United States from 1915 to 1980 against the 3 month Treasury Bill rate. (Both series are annual averages) ${ }^{2}$ This clear negative relation has been documented many times in empirical studies of money demand. These studies have typically ignored the distinction between the currency and deposit components of M1. In a sense, there was no need to address the composition issue since currency remained close to $25 \%$ of deposits during the period: See Figures 1.b and 1.c. All three figures show the clear, negative relationship to the Tbill rate.

As Figure 2.a shows, an important change occurred sometime in the early eighties. This figure extends Figure 1.a from 1981 to 2012, with data from the latter period shown in black-filled circles. Is this breakdown also reflected in the components of M1? The answer is shown in Figures 2.b and 2.c: the breakdown in M1 is associated with a breakdown in the behavior of deposits, not in currency.

As described by Teles and Zhou (2005), the early eighties were a hectic period in terms of regulatory changes. After the Great Depression, and following the GlassSteagall Act and Regulation Q, commercial banks were prohibited from paying interest rates on bank demand deposits. Regulation $\mathrm{Q}$ was first relaxed slightly in 1980, when banks were allowed to pay limited interest on personal checking accounts (NOW accounts). In 1982 banks were allowed to issue interest-paying money market deposit accounts (MMDA), which could be held by some corporations as well as by households.

NOW accounts are essentially checking accounts in which certain restrictions, such

\footnotetext{
${ }^{2}$ The data base and its description are available in an appendix of the working paper version.
} 
as a minimum average balance, are imposed by banks as a condition of receiving interest on deposits. MMDA are less liquid, in the sense that a limited number of transactions (typically 6) are allowed per month. The Fed included NOW accounts in M1, together with the traditional zero-interest checking accounts. However, it included MMDA with other savings accounts, which are part of M2.

A natural question, motivated by the coincidence in timing is: how did all these regulatory changes affect household decisions regarding the relative desirability of the different components of M1? Our candidate theory will be that the changes in the regulation in the early eighties substantially increased the availability of close substitutes for deposits, but not for cash. Once these close substitutes are allowed, our theory implies that they should be included in the monetary aggregate together with cash and traditional checking accounts. As a preview of our results, we plot, in Figure 3 the newly constructed aggregate NewM1, and its opportunity cost. ${ }^{3}$

Another major change, also emphasized by Teles and Zhou, occurred during the 90s, when the sweep technology was introduced. This essentially consists of software used by banks that automatically moves funds from checking accounts to MMDA's. This change substantially reduced the cost of moving funds between these accounts and made the MMDA more attractive relative to the demand deposits. Our theory keeps the technology parameters of banks fixed for the whole period considered, so it will be silent with respect to the effect of sweeps. ${ }^{4}$ We will discuss them in more detail in Section 5.

\footnotetext{
${ }^{3}$ The new aggregate contains assets that pay interest after 1980 . The opportunity cost is defined as $\sum_{j} \alpha_{j}\left(i-i_{j}\right)$ where $\alpha_{j}$ is the share of asset $j$ in the aggregate and $\left(i-i_{j}\right)$ is the difference between the TBill rate and the interest rate paid by asset $j$.

${ }^{4} \mathrm{~A}$ more detailed description of the changes can be found in Teles and Zhou (2005).
} 


\section{THE MODEL}

Freeman and Kydland considered a cash-in-advance model with two means of payment, currency and checks, that differ in the time cost of use and in their required reserves. We extend their model and incorporate money market deposit accounts, the most important new addition to the stock of checkable deposits. To maintain the simplicity of the model, we will treat the traditional checking accounts and the NOW accounts as a single asset, just as Freeman and Kydland did. As in Figure 3 we will form the aggregate NewM1 by simply adding MMDAs to M1. MMDAs and ordinary demand deposits coexist but they are not perfect substitutes: We need to model the distinct roles that these two assets play in the payment system. We do this by applying the Freeman-Kydland approach to three rather than two means of payment.

Their model was designed to introduce erratic money supply behavior into a real business cycle model. Our objective is to understand longer run or lower frequency relations. We therefore construct a deterministic stationary equilibrium with a constant technology for producing goods and a constant, perfectly foreseen growth rate in the supply of outside money. In this case the nominal interest rate $r$ will be the Fisherian sum $\rho+\pi$ of the subjective, real discount rate and the money growth rate $\pi$. Since these components are exogenous in our set-up, we can express equilibrium relations in the steady state as functions of $r$. We view episodes of U.S. monetary history as temporary steady states that differ in a systematic way with differences in $r$. Then we compare the model's predictions to the actual behavior of prices and monetary aggregates determined by actual interest rate movements.

We turn to the details, beginning with preferences. Households consume a contin-

uum of different goods in fixed proportions. Goods come in different "sizes," with production costs and prices that vary in proportion to size. Let $z>0$ be the size 
of a good, $F(z)=\int_{0}^{z} f(x) d x$ be the fraction of goods of size less than or equal to $z$, and let $f(z)$ be the associated density. Let $\nu=\int_{0}^{\infty} z f(z) d z$. Consuming $x$ means purchasing $\frac{z}{\nu} x$ units of each good of size $z$, so

$$
x_{t}=\int_{0}^{\infty} x_{t} \frac{z}{\nu} f(z) d z=x_{t} \frac{\int_{0}^{\infty} z f(z) d z}{\nu} .
$$

This specification is equivalent to a Leontieff aggregator for consumption of the form

$$
x_{t}=\min _{z \in[0, \infty)}\left\{\frac{\nu x_{t}(z)}{z}\right\} \text {. }
$$

All households have the common preferences over the perishable good $x_{t}$, of the form

$$
\sum_{t=0}^{\infty} \beta^{t} U\left(x_{t}\right), \quad \beta=\frac{1}{1+\rho} .
$$

Each household has one unit of labor each period, to be divided between production and cash management. For now, we treat both activities as carried out by the household. A household must buy goods from other households and sell what it produces itself to others.

We next spell out the payments technology in which these three kinds of liquid assets are used. We assume, in the manner of Baumol (1952) and Tobin (1956), that households choose the number $n$ of "trips to the bank" that they take during a period. The availability of three payment methods complicates the nature of these trips. We follow Freeman and Kydland and assume that each period is divided into $n$ stages that are identical in all respects. At the beginning of a year, a household begins with $M$ dollars. These holdings are the economy's entire stock of base or outside money. These dollars are divided into currency $C$ and bank deposits, $\theta^{d} D$ and $\theta^{a} A$, where $D$ is the level of demand deposits, $A$ is the level of MMDA's, and $\theta^{d}$ and $\theta^{a}$ are the associated required reserve ratios. These deposits are augmented with loans by the bank to increase the household's deposits, against which checks can be written, to levels $D$ and $A$. During the first of the $n$ subperiods, all of this currency and bank 
deposits will be spent on consumption goods. During this same initial period another member of the household produces and sells goods in exchange for cash and checks. At the end of the subperiod, producers visit a bank, checks are cleared, base money is divided as before, reserves, loans and deposits are renewed, and the situation at the beginning of the second subperiod replicates exactly the situation at the beginning of the first. This process is repeated exactly $n$ times during the year. ${ }^{5}$

We assume that all three payment modes are completely reliable, in the sense that sellers will accept payment in all of them, and that all modes involve the same "trip to the bank" time costs for buyers. Beyond these similarities, the three technologies have some different costs and benefits from a buyer's viewpoint. Money held as currency is subject to risk of theft or loss: We assume that a fraction $\tau \geq 0$ of each unit of currency held vanishes each period. Payments by either kind of deposit account are secure from these losses. ${ }^{6}$ Both deposit types require a labor cost proportional to the number (not the value) of checks processed that will be assumed higher for the MMDA than for ordinary checking accounts. We denote these costs per check by $k^{d}$ for demand deposits and $k^{a}$ for MMDAs, and assume that $k^{d}<k^{a}$.

On the other hand, deposits require a fraction of cash being held idle as reserves. We assume that the fraction of cash required by demand deposits, $\theta^{d}$, is higher than the one required by the MMDA's, $\theta^{a}$. Thus, while payments with demand deposits are cheaper to process, they require a larger fraction of reserves and they may both

\footnotetext{
${ }^{5}$ Notice the only payments in this model are for household purchases of final goods. The model omits the use of cash to pay employees and suppliers of intermediate goods and to clear asset exchanges. We are implicitly treating all these payments - together much larger than final goods payments - as proportional to final goods payments. This will require introducing a constant of proportionality as another free parameter in the calibration of the model.

${ }^{6}$ Allowing for $\tau>0$ is essential to have deposits held in equilibrium in our model of the regulation Q period. As we will see, it also implies that real money balances exhibit a satiation point at zero interest rates.
} 
be held in equilibrium. We will seek equilibria with two cutoff values $\delta>\gamma>0$ such that sizes between 0 and $\gamma$ are paid for by cash, sizes between $\gamma$ and $\delta$ are paid for by demand deposits, and sizes larger than $\delta$ are paid for by MMDA's. ${ }^{7}$ These cutoffs will be determined endogenously and will depend on the interest rate.

A household has one unit of time per period. The marginal product of labor-the single input - in units of the consumption good is given by the constant $y$. Total time allocated to both types of check processing is given by

$$
x\left[k^{d}(F(\delta)-F(\gamma))+k^{a}(1-F(\delta))\right] .
$$

Bank trips add $\phi n$. The rest is allocated to production, so consumption will be given by

$$
y(1-\phi n)-x\left[k^{d}(F(\delta)-F(\gamma))+k^{a}(1-F(\delta))\right]=x .
$$

The monetary base $M$ will be assumed to grow at a constant rate $\pi$ by means of lump sum transfers $\pi M$ to each household. We let $m$ denote a household's relative holdings of base money, so that in equilibrium $m=1$. We renormalize money holdings every period. Let $p=P / M$ be the normalized price of goods and, similarly, let $c=C / M, d=D / M$ and $a=A / M$. For symmetry in the analysis, we define $\theta^{c}=$ $(1-\tau)^{-1}$, so that $\theta^{i}, i=c, d, a$ is the amount of base money one needs to hold for each dollar of payment made in mode $i$. Note that $\theta^{c} \geq 1$ and $\theta^{d}, \theta^{a}<1$.

Required reserves are $\theta^{d} d+\theta^{a} a$ so base money is

$$
c \theta^{c}+\theta^{d} d+\theta^{a} a \leq m .
$$

We view each household as operating its own "bank" but still subject to a governmentimposed reserve requirement. In the next section we will decentralize this allocation and explicitly assign different functions to households and banks. If we let

$$
\Omega(\gamma)=\frac{1}{\nu} \int_{0}^{\gamma} z f(z) d z
$$

\footnotetext{
${ }^{7}$ Below we provide a necessary and sufficient condition for both assets to be held in equilibrium.
} 
be the fraction of total purchases paid for in cash, expressed as a function of the cutoff level $\gamma$, the cash constraints facing this consolidated household/bank are

$$
\begin{gathered}
n c \geq p x \Omega(\gamma), \\
n d \geq p x[\Omega(\delta)-\Omega(\gamma)], \\
n a \geq p x[1-\Omega(\delta)] .
\end{gathered}
$$

The law of motion for money balances is

$$
m^{\prime}=\frac{m+T+p y(1-\phi n)-p x\left(k^{d}(F(\delta)-F(\gamma))+k^{a}(1-F(\delta))+1\right)-\left(\theta^{c}-1\right) c}{1+\pi}
$$

Notice that the function $F$ measures numbers of transactions while $\Omega$ measures numbers of dollars. Note also that the "lost" currency $\tau c \frac{1}{1-\tau}=\tau c \theta^{c}=\left(\theta^{c}-1\right) c$ does appear as a negative item of the right. The variable $T$ denotes the lump sum transfers, that include these cash balances lost and increases the total quantity of base money by $1+\pi$. The household Bellman equation is

$$
V(m)=\max _{x, c, d, a, n, \gamma, \delta}\left\{U(x)+\beta V\left(m^{\prime}\right)\right\}
$$

subject to $(3)-(6)$. The first order plus envelope conditions evaluated at the steady state imply

$$
\begin{gathered}
\theta^{c} c+\theta^{d} d+\theta^{a} a=\frac{n p y \phi-\left(\theta^{c}-1\right) c}{r} \\
n k^{d}=\left(\left(\theta^{c}-1\right)+r\left(\theta^{c}-\theta^{d}\right)\right) \frac{1}{\nu} \gamma \\
\left(k^{a}-k^{d}\right) n=r \delta \frac{1}{\nu}\left(\theta^{d}-\theta^{a}\right)
\end{gathered}
$$

The last two imply

$$
\delta=\frac{\left(k^{a}-k^{d}\right)}{k^{d}} \frac{\left[\frac{\left(\theta^{c}-1\right)}{r}+\theta^{c}-\theta^{d}\right]}{\left(\theta^{d}-\theta^{a}\right)} \gamma \equiv h(r) \gamma
$$

A necessary and sufficient condition for all three assets to be held in equilibrium is that $h(r)>1$. 
A steady state equilibrium with positive interest rates must also satisfy feasibility (2), the cash-in-advance constraints $(4)-(6)$ and the distribution of base money condition (3) must hold with equality. The normalized base money is 1.

We can combine all these equations and obtain

$$
\begin{gathered}
\gamma \frac{1}{\nu} \frac{\left[\left(\theta^{c}-1\right)+r\left(\theta^{c}-\theta^{d}\right)\right]}{n}=k^{d} \\
\frac{n^{2} \phi}{(1-\phi n)}=\frac{r \theta^{a}+\left[\left(\theta^{c}-1\right)+r\left(\theta^{c}-\theta^{d}\right)\right] \Omega(\gamma)+r\left(\theta^{d}-\theta^{a}\right) \Omega(h(r) \gamma)}{\left[1+k^{d}(F(h(r) \gamma)-F(\gamma))+k^{a}(1-F(h(r) \gamma))\right]}
\end{gathered}
$$

These two equations determine the steady state values of $(n, \gamma)$. Then we can use (10) to solve for $\delta$.

Given the solution, we can construct theoretical counterparts of observables, as follows: The ratio of money to output is given by

$$
\begin{aligned}
\frac{\theta^{c} c+d+a}{p x} & =\frac{\theta^{c} p x \Omega(\gamma)+p x[\Omega(\delta)-\Omega(\gamma)]+p x[1-\Omega(\delta)]}{p x n} \\
& =\frac{1+\left(\theta^{c}-1\right) \Omega(\gamma)}{n} .
\end{aligned}
$$

As acknowledged in footnote 5, we are implicitly treating all these payments as proportional to final goods payments. This requires an additional constant of proportionality, that we make explicit in our calibration.

The ratios of currency to money and deposits to total deposits are given by

$$
\frac{c}{a+c+d}=\Omega(\gamma)
$$

and

$$
\frac{d}{a+d}=\frac{[\Omega(\delta)-\Omega(\gamma)]}{[1-\Omega(\gamma)]}
$$

\section{Discussion of the solution}

The household makes only two relevant decisions: the number of trips to the bank per unit of time, and the thresholds that determine the transactions to be made with cash and with each deposit type. 
Equation (12) summarizes the optimal conditions for $n$, the number of trips to the bank. Note that if the thresholds $\gamma, \delta$ were exogenous, we could write the condition as

$$
\frac{n^{2}}{1-\phi n}=f(r, \gamma, \delta)
$$

which is the typical quadratic solution associated with a Baumol-Tobin type-model. It has only one positive solution $n(r)$ which increases as $r$ increases, implying a negative relationship between real money balances - the inverse of $n$ - and the nominal interest rate. Indeed, if the thresholds were fixed, the only relevant decision of households is the number of trips to the Bank and the model becomes a Baumol-Tobin model in which each of the transactional assets is proportional to the money supply.

Equation (11) summarizes the decision with respect to the threshold $\gamma$. The lefthand side is the proportional cost of using cash plus the foregone interest for a transaction of relative size $\gamma / v$. The right-hand side is the fixed labor cost of using demand deposits, which is independent of the size of the transaction. Thus, for transactions lower than $\gamma$, the direct plus foregone interests are lower than the fixed cost, so cash is the best asset to use.

When both $n$ and $\gamma$ are chosen by households there are more possibilities. These are shown in Figure 4.a: Equation (12) is the increasing quadratic one, with a positive intercept at $\gamma=0$ and a finite asymptote as $\gamma \rightarrow \infty .^{8}$ Equation (11) is the straight line that goes through the origin. An equilibrium exists for $r \geq 0 .{ }^{9}$ Figure $4 . b$ illustrates the behavior of the equilibrium pair $(n, \gamma)$ as $r$ increases, shifting both curves upward. For the case shown in the figure, $n$ increases and $\gamma$ decreases as the interest rate increases. Both real money balances and the ratio of currency to money

\footnotetext{
${ }^{8}$ The positive solution of the quadratic equation is increasing because the right hand side of (12) is increasing in $\gamma$, and it asymptotes a finite value when $\gamma \rightarrow \infty$ since its limit is $\phi^{-1}\left(r \theta^{c}+\left(\theta^{c}-1\right)\right)$.

${ }^{9}$ If $\theta^{c}=1$, then $n \rightarrow 0$ as $r \rightarrow 0$, since equation (11) becomes the vertical axes, and real money balances do not have a satiation point.
} 
balances decrease. But there is a possibility (not shown) that for some parameter values, either of the two effects of an increase in $r$ could go the other way (though not both at the same time). In particular, the model allows for a non-monotonic relationship between real money balances and the short term interest rate.

Notice that the interaction between the two decisions affects the value of the interest rate elasticity or real money balances. Consider again, in Figure 4.b, the movement from a low interest rate to a high interest rate. Imagine for a moment that the value of $\gamma$ were fixed, at the solution for the low value of the interest rate. If this were the case, when the interest rate rises the solution for $n$ would be given by point A in Figure 4.b. But the value of $\gamma$ goes down: We can think of the effect of this adjustment in $\gamma$ as the movement from point $\mathrm{A}$ towards point $\mathrm{B}$. This increase in the share of transactions made with deposits - that pay interest - implies that the overall opportunity cost of money balances goes up by less than what would be the case with a fixed value for $\gamma$. This explains the lower response in $n$ once we take into account the endogenous effect of the interest rate on the choice between deposits and cash.

\section{A note on the effects of growth.}

The solution of the system (12) and (11) is invariant to changes in the marginal product of labor, $y$. By (2), total consumption grows if productivity and output grow, and therefore the number of transactions grow. However, the total number of hours devoted to effecting transactions is the same, so productivity is growing for both good producing activities and for transactions activities at the same rate. Thus, the model can be applied to a growing economy as the US during the last century, as long as productivity growth is the same in the both sectors.

\section{DECENTRALIZATION}

We have developed an equilibrium by treating production and banking services as different functions carried out within a single household. But in this constant returns 
environment, we can scale these activities up or down and decentralize them into banks and households. With free entry and competitive pricing - including interest rates on demand deposits - the decentralized equilibrium coincides with the results of Section 3. We then use the decentralized model to consider the effects of Regulation Q: the prohibition of interest payments on commercial bank deposits.

To carry this out, we need to allocate the two payment activities, "trips to the bank" $\phi n$ and "check processing" $k(1-F(\gamma))$ between banks and households. As in Section 3 we assume that "trips" are a household activity that does not appear in the national accounts or as employment, and that banks process checks using labor hired from households at the equilibrium wage $P y \cdot{ }^{10}$ Households pay the bank a fee $Q^{j}=M q^{j}, j=d, a$ per check processed from demand deposits and MMDAs respectively. The technology of check processing is unchanged.

As before, the normalized monetary base is divided into currency and reserves held against deposits. The deposit of $\theta d$ entitles the depositor to withdraw $d$ in checks. We treat this as a loan of $(1-\theta) d$ to the household by the bank, entitling the bank to $r(1-\theta) d$ at the end of the period. If the bank pays interest at a rate $r_{d}$ on deposits the net interest cost to the household of setting up a deposit of size $d$ is $\left(r(1-\theta)-r_{d}\right) d$. In a similar fashion, the net interest cost to the household of setting up a deposit of size $a$ is $\left(r(1-\theta)-r_{a}\right)$. Finally, if the bank should make a profit this would be paid as a lump sum $\Pi$ to households in their capacity as shareholders. The numbers $\left(q^{d}, r_{d}, q^{a}, r_{a}, \Pi\right)$ are taken as given by depositors. Their equilibrium values will be determined below. As before, monetary policy is executed via a lump sum transfer $T$.

The flow budget constraint facing the household is then

$$
(1+\pi) m^{\prime}=m+T+\left(r_{d}-r\left(1-\theta^{d}\right)\right) d+\left(r_{a}-r\left(1-\theta^{a}\right)\right) a-\left(\theta^{c}-1\right) c
$$

\footnotetext{
${ }^{10}$ These assumptions imply that all fixed costs of transactions acrrue within banks. This is not essential for the analysis that follows. We will allow for a more general sructure in Section 6 .
} 


$$
+\Pi+p y(1-\phi n)-p x-q^{d} x(F(\delta)-F(\gamma))-q^{a} x(1-F(\delta))
$$

The household's Bellman equation is

$$
v(m)=\max _{x, c, d, a, \gamma, \delta, n}\left\{U(x)+\beta v\left(m^{\prime}\right)\right\}
$$

subject to (3) and the cash constraints (4) - (6). As in Section 3 we obtain the firstorder and envelope conditions, eliminate multipliers, and impose the steady state condition $m=m^{\prime}=1$ to obtain

$$
\begin{gathered}
n \frac{q^{d}}{p}=\frac{\gamma}{v}\left[\left(\theta^{c}-1\right)+r \theta^{c}-\left(r_{d}-r\left(1-\theta^{d}\right)\right)-r \theta^{d}\right] \\
n \frac{\left(q^{d}-q^{a}\right)}{p}=\frac{\delta}{\nu}\left[\left(r_{d}-r\left(1-\theta^{d}\right)\right)+r \theta^{d}-\left(r_{a}-r\left(1-\theta^{a}\right)\right)-r \theta^{a}\right] \\
\frac{n}{r} p y \phi=r+\left[\left(\theta^{c}-1\right) c+d\left(r_{d}-r\left(1-\theta^{d}\right)\right)+a\left(r_{a}-r\left(1-\theta^{a}\right)\right)\right]
\end{gathered}
$$

Bank profits will be

$$
\begin{aligned}
\Pi= & p x[\Omega(\delta)-\Omega(\gamma)]\left(r\left(1-\theta^{d}\right)-r^{d}\right)+[F(\delta)-F(\gamma)]\left(\frac{q^{d}}{p}-k^{d}\right) \\
& +p x[1-\Omega(\delta)]\left(r\left(1-\theta^{a}\right)-r^{a}\right)+[1-F(\delta)]\left(\frac{q^{a}}{p}-k^{a}\right)
\end{aligned}
$$

If Banks set fees and pays interest according to

$$
\frac{q^{d}}{p}=k^{d}, \quad \frac{q^{a}}{p}=k^{a}, \quad r_{d}=\left(1-\theta^{d}\right) r, \quad r_{a}=\left(1-\theta^{a}\right) r
$$

they make zero profits. Then the first three conditions become the same as equations (7) - (9) in Section 3. As the constraints are also the same, the equilibrium allocation is the same.

This equivalence between a decentralized equilibrium and a relatively centralized one is familiar, but of course it depends on prices being market-determined. In our application, this equivalence was broken due to the prohibition of interest payments on commercial bank deposits due to Regulation Q, in force nominally from 1935 until 
2011. Even taking into account the partial deregulations of 1980-1982, we are left with a period from 1935 to 1980 during which restrictions on interest rates probably had allocative effects. In the next section we will set aside the complications raised by Regulation Q and calibrate and simulate the model developed in Sections 3 and 4. In Section 6, we explicitly model the distortions induced by Regulation Q and discuss their implications for M1 and our NewM1.

\section{CALIBRATION AND SIMULATION}

The predictions of the basic model take the form given in equations (13)-(15), where the functions $n(r), \gamma(r)$ and $\delta(r)=h(r) \gamma(r)$ are defined in (12), (11) and (10). For each interest rate level $r$, these three functions describe the corresponding steadystate behavior implied by the theory. In order to see how well this behavior matches up to U.S. time series we need to provide parametric descriptions of the functions $F$ and $\Omega$ and values for the parameters $\theta^{c}, \theta^{d}, \theta^{a}, k^{d}, k^{a}$ and $\phi$. To do this, we draw on observations on currency, demand deposits, money market demand deposits, required reserve ratios, short term interest rate, the size of the banking sector, and nominal GDP, as described below.

For the distribution $F$ of transaction sizes, we let the density be

$$
f(z)=\frac{\eta}{(1+z)^{1+\eta}}, \quad \eta>1
$$

which implies that there are more small size transactions than large ones, as indicated by data on check payments. ${ }^{11}$ This one-parameter density implies

$$
F(\gamma)=1-\frac{1}{(1+\gamma)^{\eta}} \quad \text { and } \quad \Omega(\gamma)=1-\frac{1+\gamma \eta}{(1+\gamma)^{\eta}}
$$

We add the parameter $\eta$ to the list of constants to be calibrated. It will sometimes be

\footnotetext{
${ }^{11}$ See, for instance, "The 2010 Federal Reserve Payments Study", pg. 27, http://www.frbservices.org/files/communications/pdf/research/2010_payments_study.pdf. .
} 
convenient to make explicit the dependence of the functions $F$ and $\Omega$ on the parameter $\eta$ and write $F(\gamma, \eta)$ and $\Omega(\gamma, \eta)$.

For the values $\theta^{c}, \theta^{d}$ and $\theta^{a}$ we assume $\theta^{c}=1.01, \theta^{d}=0.1$ and $\theta^{a}=0.01$. The figure for $\theta^{d}$ is about the right magnitude for required reserves in the post-war period. We chose a much smaller (but still positive) reserve ratio for MMDAs. The value $\theta^{c}$ for currency would be 1 if currency were as safe as deposits. We chose a "loss rate" of 0.01 , loosely based on Alvarez and Lippi (2009)..$^{12}$

The three labor cost parameters $k^{d}, k^{a}$ and $\phi$ and the parameter $\eta$ of the transactions distribution are all assumed to be constant, but we have no direct evidence on any of them. We calibrate these indirectly, using the year 1984 as a benchmark. 1984 is the first year for which we have separate data on MMDA's, and two years after the MMDA's were permitted in the U.S. Two years was probably enough time for banks and others to adjust to the new instrument and to move funds from demand deposits to MMDA's.

The Tbill rate in 1984 was $9.5 \%$. That same year, the ratio of currency to total money holdings was $17 \%$ and the values of demand deposits and MMDAs were approximately equal. Then (14) and (15) imply

$$
\frac{0.17}{1.01}=\Omega(\gamma(.095), \eta)
$$

and

$$
1-\Omega(\delta(.095), \eta)=\Omega(\delta(.095), \eta)-\Omega(\gamma(.095), \eta) .
$$

To complete the calibration, we estimated the fraction of resources used in carrying out transactions flows. Here we think of $\phi n$ as household time, not included in measured GDP, and think of the labor costs per checks cleared, $k^{d}$ and $k^{a}$, as bank employee time. We can think of Phillipon's (2008) estimate of 0.05 as a bound on the

\footnotetext{
${ }^{12}$ The number they find for Italy is $2 \%$. We chose half of that number for the US and performed some robustness checks.
} 
fraction of GDP generated in the financial sector, but the fraction devoted to payment activities will be much less. We assume that total output spent on check processing at banks for both deposit types is $1 \%$ of GDP. We also assume that total time spent by households in trips to the bank is $1 \%$ of GDP. ${ }^{13}$ With these assumptions, the following equations must hold for 1984:

$$
k^{d}(F(\delta(0.095))-F(\gamma(0.095)))+k^{a}(1-F(\delta(0.095)))=0.01
$$

and

$$
\phi n(0.095)=0.01
$$

Equations (16) - (19) plus the equilibrium conditions (10)-(12) evaluated at $r=0.095$ then serve as 7 equations in the variables $\gamma(0.095), \delta(0.095), n(0.095)$ and the unknown parameters $\phi, k^{d}, k^{a}$ and $\eta$.

With the constant parameters determined, we then use the calibrated versions of $(10)-(11)$ to solve for the functions $n(r), \gamma(r)$ and $\delta(r)$. Finally, we use the free scale parameter $\Delta$ as an intercept, chosen so the theoretical curve

$$
\frac{c+d+a}{p x}=\frac{\Delta}{n(r)}
$$

crosses the point $\left(r, m_{1}\right)=(0.06,0.25)$. Our theory is therefore seen to have implications only on the slope of the real money demand.

The resulting values for the parameters are $\phi=0.0057, \eta=1.56, k^{d}=0.030$, $k^{a}=0.049$, and $\Delta=0.414$. Figure 5.a shows the evolution of the cash to deposit ratio predicted by the model when we fit in the observed interest rates from 1984 to 2012 in the black line with crosses, and the observed value for the cash to deposit ratio for the same period, in the solid line. This was a period with a downward trend in interest rates, but with very large, high-frequency fluctuations in the short

\footnotetext{
${ }^{13}$ We will consider alternative targets and study the robusteness of the results to these numbers.
} 
term interest rate. The model does capture the overall increasing pattern of the cash to deposit ratio, but data exhibits much less volatility than the model predicts. At this level, the model clearly fails. This is not completely surprising. It is well known that money demand models like the ones we consider in this paper fail to match the behavior of real money demand at high frequencies, in the sense that temporary changes in short term interest rates have relatively little impact on real money balances. ${ }^{14}$

Figure $5 . b$ reproduces this exercise, but compares the low frequency component of the cash to deposit ratio with the solution implied by the model when we feed into it the low frequency component of the short term interest rate. In both cases, we filtered the data using the Hodrick-Prescott filter with a smoothing parameter of 100. As the graph shows, the model does capture remarkably well the upward trend exhibited in the data for the first two decades, but then misses by a large margin in the last one, when interest rates were very low.

To interpret the previous two figures, we need to clarify the way we treat the sweep programs that were introduced in $1994 .^{15}$ There are two types of sweeps: The first, "retail sweeps," are essentially accounting strategies used by banks to reduce their required reserves. Deposit holders may not even be aware of this. The second type, "commercial demand deposit sweeps," reflect substitution decisions made by deposit holders. Since we are interested in the demand side of deposits, we measure demand deposits as the sum of the official figures provided by the Federal Reserve plus the

${ }^{14} \mathrm{M} 1$ to GDP did not respond at all to the short-lived reductions in interest rates in $71-72$ and 75-76. Interestingly, NewM1 does respond (though by a small quantity) to the temporary drops in 86-87 and 92-93. Our model does not provide any insight on this feature. Attempts at explaining this feature go back at least as early as the models of Rotemberg (1984) and Grossman and Weiss (1983).

${ }^{15}$ For a very good and detailed description of the sweeps, see Cynamon et. al. (2005). 
total of the retail sweeps. We included the commercial demand deposit sweeps as MMDA. ${ }^{16}$

Figure 5.c is similar to 5.a, but it measures the ratio of demand deposits to money market demand accounts. As before, the model clearly misses at the high frequency. Figure 5.d, displaying low frequencies only, shows that the model reproduces the trend in the data, but only until the mid-nineties. From there on, the ratio of demand deposits to total deposits falls dramatically, while the theory predicts that it should keep on increasing. As we discussed in Section 2, we believe that the sweep technology introduced in 1994 and that became very popular by the end of the 90's explains the significant decline of demand deposits relative to MMDA observed in the data. Our constant-technologies model is unable to capture this feature. In summary, when considering the behavior of the ratio of the components of NewM1, the model produces mixed results relative to the data.

Finally, in Figure 6, we plot the calibrated theoretical curve for real money balances as a function of the nominal interest rate, together with the data for the unregulated periods (1915-1935 and 1983-2008). ${ }^{17}$ We set the free parameter $\Delta$ so that the curve passes through the point $(0.06,0.25)$, but no information regarding slopes was used in the calibration. Nonetheless, the theoretical curve reproduces the data very well.

We find it remarkable that in spite of the mixed results regarding the ratio of the components of NewM1 after the middle of the 90's, no sign of instability is detected for aggregate money balances. The very large shifts we see between demand deposits and money market demand accounts since 1995, are not reflected in the relation

\footnotetext{
${ }^{16}$ Further details can be found in the data Appendix of the Working Paper version.

${ }^{17}$ Note that the theoretical model takes into account the fact that the choices of each asset are endogenous. Still, the relationship derived relates the monetary aggregate to the nominal interest rate, not to the opportunity cost of holding money. It clearly does take into account the substitutions within the aggregate implied by the model.
} 
between the short term interest rates and money balances over GDP between 1995 and 2012 .

This is also the case in the model, which exhibits a strong robustness of the overall money balances to GDP to the many parameters, such as the parameters of the banking technologies, that affect very critically the behavior of each of the components. We performed several robustness exercises. Here we describe one of these that seems particularly suited for this discussion. We simulated the model for four different values of the parameter $k^{a}$, while keeping constant all other parameters. Calibration 1 will refer to the one we used so far. Calibrations 2, 3 and 4 use the same parameters, except that $k^{a}, 0.049$ in the original calibration, takes correspondingly the values 0.0466, 0.0433 and 0.0400 in the new calibrations. These differences imply that the ratio $k^{a} / k^{d}$ goes from almost $5 / 3$ to $4 / 3$.

Figure 7.a, which shows the low frequencies only, can be compared to Figure 5.d. Calibration 1 is the original one, which tracks the data well for the first part of the sample. As the assumed fixed cost of transacting with the money market demand accounts is reduced, relative to the demand deposits, the cutoff for transactions with MMDA goes down, and the ratio of demand deposits to total deposits goes down. ${ }^{18}$ Figure $7 . b$ shows the effects of these parameter changes on total balances. Intuitively, as the cost of making transactions with MMDA's goes down, the overall opportunity cost of money balances goes down and real money balances do go up. But the change is not nearly as dramatic as it is for the ratio of demand deposit to total deposits.

We also explored the robustness of the model to other changes in the targets for the calibration. We experimented with both the fraction of GDP used in transactions and the value of time spent by households in transactions for the case when interest rates are close to $10 \% .{ }^{19}$ Our benchmark calibration used a value of $1 \%$ in both cases.

\footnotetext{
${ }^{18}$ Note that the behavior at very low rates is independent of the calibration. This implies that the model will have a hard time matching this ratio for near zero interest rates.

${ }^{19}$ The matlab program "robustness.m" on the website of the paper can be used to solve the model
} 
Similar results are obtained for the equilibrium values if both numbers are set to $2 \%$, or if the fraction of GDP used in transactions is left at $1 \%$ and the value of time spent by households is varied from $1.25 \%$ to $0.75 \%$. Some plots get better, others get worse, but the general message is the same: While the ability of the model to match the ratios between the components of NewM1 is mixed, the behavior of the aggregate is remarkably close to the data.

Figure 6 focuses on the periods when regulation $Q$ was not in place, the years that are closest to meeting the assumptions of the model developed in Section 3. We now consider, in the next section, a possible model of bank competition with legal caps on interest rates banks can pay. However, it is instructive to compare the data during the regulation Q period, with the theory developed so far, which we do in Figure 8.a. The theoretical curve overpredicts money balances - alas, because of regulation, the theory is not the correct one. In other words, the elasticity of real money balances with respect to the interest rates was higher during the regulation $\mathrm{Q}$ period than the one implied by the model (and observe during the unregulated period). As we will see in the next Section, this is consistent with the model.

\section{REGULATION Q}

\subsection{Theory}

As we remarked at the end of Section 4, the basic model of Sections 3 and 4 does not deal with the distortions induced by Regulation Q. This omission also applies to the simulations reported in Section 5. In this section, we propose a possible model of banking competition under regulation $\mathrm{Q}$, interpreted as imposing a ceiling, $\bar{r}=0$ on the rate banks can pay on deposits. If we assume that this regulation would also apply to MMDAs, so that MMDAs would not be allowed to pay a higher interest rate for different values of the targets. 
than other deposits, they lose their relative advantage and we can ignore them by setting $\delta \rightarrow \infty$.

The key idea we pursue in this section is that if banks are unable to pay interest on deposits, they will compete by offering reduced check-processing fees. We treat each transaction size as a different product, and the fees will be determined by the zero profit condition product by product. However, we impose the restriction that fees cannot be negative. Thus, for a given transaction size, the higher is the interest rate, the lower will be the fee charged by the bank for that transaction, to the point in which the interest income suffices to fully cover the fixed transaction cost. For higher interest rates banks will make positive profits, so some form of entry restriction must prevail for this outcome to be consistent with an equilibrium. As suggested by this discussion, the way the fixed costs $k^{d}$ are borne by the household or the bank becomes important. Thus, we let $k^{d}=k^{b}+k^{h}$, where $k^{b} \geq 0, k^{h} \geq 0$.

The details are as follows. Suppose there are $x f(z)$ checks to be processed at transaction size $z$ and $p x z f(z) / v$ dollars spent. These flows require $p x z f(z) /(v / n)$ in deposits and entail $p x f(z) k^{b}$ in check processing costs. When the excess of interest income over cost at the transaction size $z$ is positive, the depositor is charged no fee and the bank collects

$$
\pi(z)=\operatorname{pxf}(z)\left[r\left(1-\theta^{d}\right) \frac{1}{\nu} \frac{z}{n}-k^{b}\right]
$$

in profit income. When it is negative, the depositor is charged with processing fees equal to

$$
p x f(z)\left[k^{b}-r\left(1-\theta^{d}\right) \frac{1}{\nu} \frac{z}{n}\right]
$$

for all checks of size $z$ issued, and the bank collects no profit income. Thus, for a check of size $z$, the fee per-check in equilibrium must satisfy

$$
\frac{q(z)}{p}=\max \left\{\left[k^{b}-r\left(1-\theta^{d}\right) \frac{1}{\nu} \frac{z}{n}\right], 0\right\}
$$


Consumers see contracts such that

$$
r\left(1-\theta^{d}\right) \frac{p x}{n}[1-\Omega(\gamma)]
$$

is the amount of money that cost them to borrow deposits equal to $(p x / n)[1-\Omega(\gamma)]$. In addition, they take as given the function $q(z)$ that indicates the fee they pay for each check of size $z$. The total transactions cost for them is given by

$$
\int_{\gamma}^{\infty}\left(\frac{q(z)}{p}+k^{h}\right) p x f(z) d z
$$

Adding the two components, we define the total cost to consumers for using deposits as

$$
M(n, \gamma) \equiv \int_{\gamma}^{\infty}\left(\frac{q(z)}{p}+k^{h}\right) f(z) d z+r\left(1-\theta^{d}\right) \frac{1}{n}[1-\Omega(\gamma)] .
$$

A depositor's Bellman equation in this situation is

$$
V(m)=\max _{x, \gamma, n}\left\{U(x)+\beta V\left(m^{\prime}\right)\right\}
$$

subject to the cash constraint

$$
p x\left(\theta^{c} \Omega(\gamma)+\theta^{d}[1-\Omega(\gamma)]\right) \leq m n,
$$

where

$$
m^{\prime}=\frac{m+\pi+\Pi+p y(1-\phi n)-p x-\left(\theta^{c}-1\right)(p x / n) \Omega(\gamma)-p x M(n, \gamma)}{1+\pi} .
$$

Here $\Pi$ represents the profits banks may make in equilibrium.

As before, the first order and envelope conditions evaluated at the steady state, plus all other equilibrium conditions can be arranged to obtain two equations that solve for $n$ and $\gamma$,

$$
n \max \left\{\left[k^{b}-r(1-\theta) \frac{1}{\nu} \frac{z}{n}\right]+k^{h}, k^{h}\right\}=\gamma \frac{1}{\nu}\left(\theta^{c}-1\right)(1+r)
$$


and

$$
\frac{n^{2} \phi}{(1-\phi n)}=\left[\frac{r\left[\theta^{c} \Omega(\gamma)+[1-\Omega(\gamma)]\right]+\left(\theta^{c}-1\right) \Omega(\gamma)}{[1+k(1-F(\gamma))]}\right]
$$

\section{Analysis of the solution.}

For the first equation, assume $k^{b}>r(1-\theta)(\gamma / v n)$, which means that the equilibrium fee is always positive at the cutoff value $\gamma$ and equal to $q(\gamma) / p>0$. Then, the first equation becomes

$$
n\left(k^{b}+k^{h}\right)=\gamma \frac{1}{\nu}\left[r\left(\theta^{c}-\theta^{d}\right)+\left(\theta^{c}-1\right)\right]
$$

which is the same equation we obtained in Section 3 (see equation (11)).

On the other hand, if $k^{b}<r(1-\theta)(\gamma / v n)$, we obtain

$$
n k^{h}=\gamma \frac{1}{\nu}\left[r\left(\theta^{c}-1\right)+\left(\theta^{c}-1\right)\right]
$$

The value $k^{b}-r\left(1-\theta^{d}\right)(\gamma / v n)$ is expressed in terms of endogenous variables so these two inequalities are hard to interpret However, it is straightforward to show that for values of $r$, such that

$$
\frac{r}{(1+r)}<\frac{\left(\theta^{c}-1\right)}{\left(1-\theta^{d}\right)} \frac{k^{b}}{k^{h}}
$$

the equilibrium value of the fee at the cutoff value is positive, $q(\gamma) / p>0$, and the solution of the system is given by

$$
n\left(k^{b}+k^{h}\right)=\gamma \frac{1}{\nu}\left[r\left(\theta^{c}-\theta^{d}\right)+\left(\theta^{c}-1\right)\right]
$$

and

$$
\frac{n^{2} \phi}{(1-\phi n)}=\left[\frac{r\left[\theta^{c} \Omega(\gamma)+[1-\Omega(\gamma)]\right]+\left(\theta^{c}-1\right) \Omega(\gamma)}{[1+k(1-F(\gamma))]}\right] .
$$

If, on the other hand, $r$ is so high that (22) is not satisfied, the solution is given by the system formed by equations

$$
n k^{h}=\gamma \frac{1}{\nu}\left[r\left(\theta^{c}-1\right)+\left(\theta^{c}-1\right)\right]
$$


and (24) and the equilibrium value of the fee at the cutoff point is zero.

We stress two features of this solution. The first is best explained by a comparison of the quadratic equation obtained here, (24), with its Section 3 counterpart, (12), based on market-determined interest rates. The latter equation is repeated here:

$$
\frac{n^{2} \phi}{(1-\phi n)}=\frac{\left(\theta^{c}-1\right) \Omega(\gamma)+r\left[\theta^{c} \Omega(\gamma)+\theta^{d}[\Omega(h(r) \gamma)-\Omega(\gamma)]+\theta^{a}[1-\Omega(h(r) \gamma)]\right]}{\left[1+k^{d}(F(h(r) \gamma)-F(\gamma))+k^{a}(1-F(h(r) \gamma))\right]}
$$

The right hand side of these equations summarizes, in each case, the interaction between the decisions regarding the cutoff point $(\gamma)$, and the number of trips to the bank. In a standard Baumol-Tobin model, in which the cutoff is fixed, the only changes in the right hand side of this equation would come about changes in the interest rate. In contrast, the inside money endogenous decisions $(\gamma)$ in both $(24)$ and (12) also change the right hand side of that equation, and does so very differently in the two cases. For (12), the range of variation of the right hand side of equation, when $\gamma$ and $\delta$ go from zero (so that $0=\Omega(\gamma)=\Omega(\delta)=F(\delta)=F(\gamma)$ ) to $\infty$ (so that $1=\Omega(\gamma)=\Omega(\delta)=F(\delta)=F(\gamma))$ is given by

$$
0.01+1.01 r-\frac{0.01}{1+0.049} r \simeq 0.01+r
$$

so it moves one to one with the interest rate. On the other hand, the range of variation in the right hand side of equation (24), is given by

$$
1.01 r+0.01-\frac{r}{1+0.03} \simeq 0.01 r+0.01
$$

or $1 / 100$ of the interest rate.

What these numbers suggest is that the feedback between the portfolio decision and the number of trips to the banks will be quantitatively very small during the regulation $\mathrm{Q}$ period, compared with the ones of the market determined interest rates period. It was this feedback that reduced the interest rate elasticity when interest rates are freely determined. As the quantitative impact of this feedback is reduced, we 
expect the interest elasticity of real money balances to be higher during the regulation Q period. ${ }^{20}$

The second feature of the Regulation Q case is the way the other equation that determines the solution behaves. This equation is given by (23) for the interest rate lower than the threshold (22) and by (25) for higher interest rates. In the first case, the equation is the same as in Section 3, so the solution is similar to that one in Section 3 , Figure 4.b: as the interest rate goes up, $n$ increases and $\gamma$ decreases. However, once the interest rate reaches the threshold, the straight line is now given by (25). This equation is much less sensitive to increases in $r$, since it is multiplied by $\left(\theta^{c}-1\right)$ instead of $\left(\theta^{c}-\theta^{d}\right)$ which is way smaller. ${ }^{21}$ Just to simplify the discussion, imagine that after the threshold, that equation is independent of the interest rate. ${ }^{22}$ Consider then increases in $r$ beyond the threshold and recall Figure 4.b: The straight line does not move, while the concave curve moves upwards. The result is an increase $n$, as before, but now, contrary to what it was the case when the interest rate was below the threshold (22), $\gamma$ goes up.

To summarize, for very low levels of the interest rate, the system behaves similar to the one in Section 3 when the interest rate goes up: the number of trips to the bank goes up (real balances go down) and the ratio of cash over money goes down. Once the interest rate reaches the threshold, further increases of the interest rate from medium to high imply an increase of $n$, but larger than before, since the now the threshold $\gamma$ increases. This also pushes the interest elasticity of real money balances up during regulation $\mathrm{Q}$ - though the quantitative impact is very small, since the concave curve is very flat. In addition the relationship between $r$ and $\gamma$ is U-shaped. As it turns out, the U-shape pattern is also exhibited in the data between 1935 and 1981 - the

\footnotetext{
${ }^{20}$ This goes in the right direction, relative to the data showed in Figure 8.a.

${ }^{21}$ For our calibration, $\theta^{c}-\theta^{d}=0.91$, while $\theta^{c}-1=0.01$.

${ }^{22}$ This will be the case when $\tau=0$, so $\theta^{c}=1$.
} 
period when regulation $\mathrm{Q}$ had full applicability. ${ }^{23}$

\subsection{Results}

We have already calibrated all parameters of the model. To evaluate its performance during the regulation $\mathrm{Q}$ period, we also need to assign values to the additional parameter, $k^{h}=k-k^{b}$. In other words, we need to split the fixed costs of making transactions (0.03 in our calibration) between banks and households, a distinction that is immaterial with market determined interest rates.

We let $k^{h}$ be such that the U-shape implied by $\gamma$ in the theory matches the minimum in the U-shape curve of the data. The results for real money balances are depicted in Figure 8.b. As argued before, the curve during the regulation Q period is steeper than the curve when deposits can pay interest rates. However, the model implies an elasticity that is higher than the one suggested by the data: our theory underpredicts money balances during the Regulation $\mathrm{Q}$ period for interest rates that are higher than $1 \%$. As before, this curve is very robust to variations in the values used for calibration.

Finally, in Figure 8.c we plot the theoretical values for the cash to money ratio for the regulation $\mathrm{Q}$ period, together with the data. As it can be seen, the model strongly over-predicts the level of the ratio. This feature, as it was the case in Section 3, is sensitive to changes in the values used for the calibration. For instance, changing the parameter $\theta^{c}$, or $k^{d}$ substantially changes the level of the cash to money ratio, while leaving essentially unchanged the slope of real money balances.

\footnotetext{
${ }^{23}$ The U-shape pattern in the data is likely affected by potentially lasting effects of the the bank panics of the 30's on one hand and the war in the other. Thus, we do not want to push this too far. However, the model does imply that for higher interest rates, there is an increasing relationship between $r$ and $\gamma$, as it is observed in the data from 1950 to 1980.
} 
As before, the behavior of each of the components is very sensitive to the banking technology in another dimension: small changes in the calibration target imply large changes in Figure 8.c. For instance, assuming that the GDP loss in trips to the bank by households $(\phi n)$ is $1.5 \%$ of output, instead of $1 \%$, improves substantially the cash to money ratio picture. On the other hand, the behavior of the real money balances is barely affected. We do not pursue this idea further. The reason we chose to calibrate the parameters so that total resources spent on fixed cost of using deposits is $1 \%$ of GDP and total transaction costs of going to the bank is $1 \%$, is not because we have estimates of those numbers. We do not. It is because, with enough effort in empirical analysis, one could obtain those aggregate estimates. And those are the right aggregate numbers to discipline the values for $k^{d}, k^{a}$ and $\phi$.

In summary, our model of banking competition during regulation $\mathrm{Q}$ goes in the right direction qualitatively: it implies that the interest rate elasticity should be higher under this regulation. However, the model overpredicts the increase in the interest rate elasticity during the period. In addition, it misses the level of cash to deposits ratio, though it can explain the increase in the relative use of cash during the increase in interest rates that occurred from 1950 to 1980. As before, the implications regarding the level of the ratio of cash to deposits is very sensitive to small changes in parameters we cannot precisely calibrate. On the other hand the behavior of the aggregate is very robust to those changes.

The data for NewM1 over GDP during the regulation Q period - which is equal to M1, since MMDA were zero before 1982 - lies between the two theoretical models considered, one with market determined interest rates and the other with an effective cap on interest rates paid by banks at zero. The evidence seems to suggest that, somehow, banks could partially circumvent the ceiling on interest rates and transfer to depositors a fraction of the return they obtained with their deposits. ${ }^{24}$

\footnotetext{
${ }^{24}$ Anecdotal evidence shows that competition drove banks to offer durable goods (toasters, TV
} 


\section{CONCLUSIONS}

We view the new aggregate NewM1 as a step toward doing for M1 what Motley (1988) and Poole (1991) did for M2 with their new aggregate MZM. Both are attempts to define redefine monetary aggregates by the functions they have in the payments system rather than by the institutions whose liabilities they are. Roughly speaking, the deposit component of NewM1 includes and is limited to deposits you can write checks on, on paper or electronically, a measure of the same thing that M1 measured in the past. The new aggregate does about as well on low and medium frequencies over the period 1915-2013 as M1 did from 1915 to 1990, as about as poorly on high frequencies.

Our application of the Freeman/Kydland model of the components of these broader aggregates, reported in Sections 3 and 6, is frankly exploratory. The whole question of the substitutability among various means of payment is captured by the distribution of transaction sizes. We have just begun to think through and test the many possibilities.

Finally, since we are writing in 2014, we should emphasize that the analysis is all based on theoretical steady states. We are trying to get the quantity theory of money back to where it seemed to be in 1980, but after all the older theories were as silent on financial crises as is this one is.

\section{References}

1. Alvarez, F. and F. Lippi. "Financial innovation and the transactions demand for cash", Econometrica, 2009

2. Baumol, William J. "The Transactions Demand for Cash: An Inventory Theoretic Approach." Quarterly Journal of Economics, 66 (1952): 545-556.

sets) to compensate loyal customers. These may have been ways to partially circumvent the prohibition to pay interests and would reduce somewaht the elasticity of money demand. They would also imply a lower cash to deposits ratio. See Gilbert (1986). 
3. Broaddus, J. and MGoodfriend. "Base Drift and the Long Run Growth of M1: Experience from a Decade of Monetary Targeting". Federal Reserve Bank of Richmond Economic Review, November/December 1984, 1-14.

4. Cynamon B., D. Dutkowsky and B. Jones. "Redefining the Monetary Aggregates: A Clean Sweep" Eastern Economic Journal, 32 (2006).

5. Freeman, Scott, and Finn E. Kydland. "Monetary Aggregates and Output." American Economic Review, 90 (2000): 1125-1135.

6. Gilbert. R. "Requiem for Regulation Q: What It Did and Why It Passed Away" Federal Reserve Bank of Saint Louis Review. (February 1986) 23-37.

7. Goodfriend, M. and M. Hargraves. "A Historical Assessment of the Rationales and Functions of Reserve Requirements", Federal Reserve Bank of Richmond Economic Review March/April 1983, 3-21.

8. Ireland, Peter N. "On the Welfare Cost of Inflation and the Recent Behavior of Money Demand." American Economic Review, 99 (2009): 1040-1052.

9. Lucas, Robert E., Jr. "Inflation and Welfare," Econometrica, 68 (2000): 247274.

10. Meltzer, Allan H. "The Demand for Money: The Evidence from Time Series," Journal of Political Economy, 71 (1963): 219-246.

11. Motley, Brian. "Should M2 be Redefined?". Federal Reserve Bank of San Francisco Economic Review, (1988), 33-51.

12. Philippon, Thomas. "The Evolution of the U.S. Financial Industry from 1860 through 2007." NYU Working Paper (2008). 
13. Poole, William. Statement Before the Subcommittee on Domestic Monetary Policy of the Committee on Banking, Finance and Urban Affairs. U.S. House of Representatives, (1991).

14. Prescott, Edward C. "A Multiple Means of Payment Model," in William A. Barnett and Kenneth N. Singleton, eds., New Approaches to Monetary Economics, Cambridge University Press (1987): 42-45.

15. Reynard, Samuel. "Financial Participation and the Apparent Instability of Money Demand." Journal of Monetary Economics, 54 (2004): 1297-1317.

16. Teles, P. and R. Zhou, "A Stable Money Demand: Looking for the Right Monetary Aggregate." Federal Reserve Bank of Chicago Economic Perspectives, (2005): 50-63.

17. Tobin, J. "The Interest Elasticity of Transactions Demand for Cash." Review of Economics and Statistics, 38 (1956): 241-247. 
Figure 1a: M1/GDP vs. Interest Rate (Three-Month T-Bill), 1915 - 1980

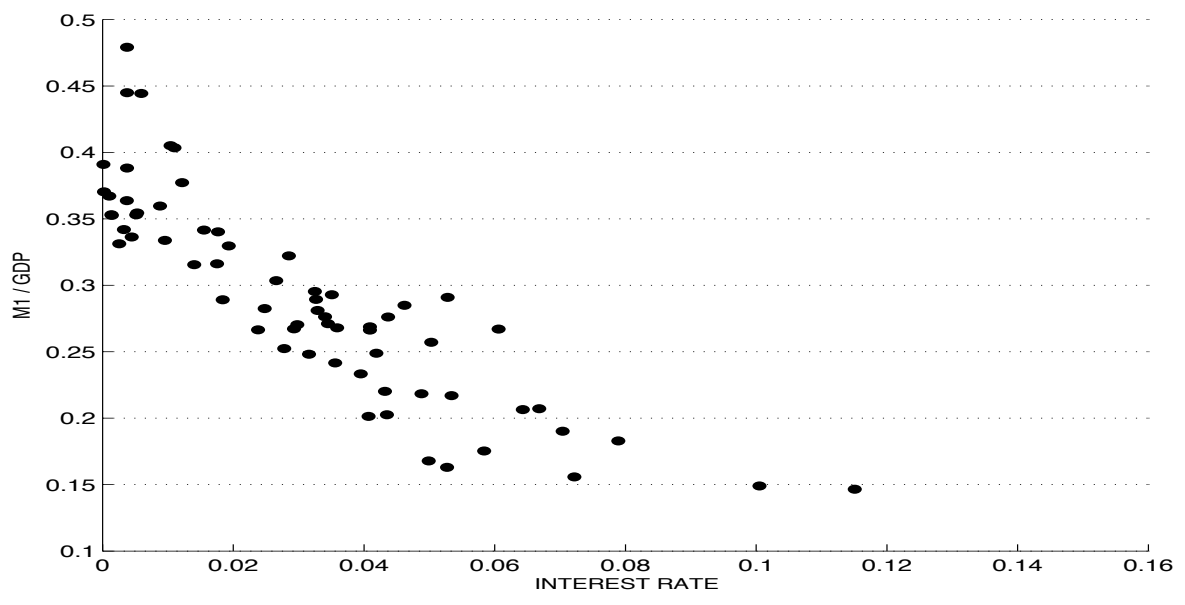

Figure 1b: Currency/GDP vs. Interest Rate (Three-Month T-Bill), 1915 - 1980

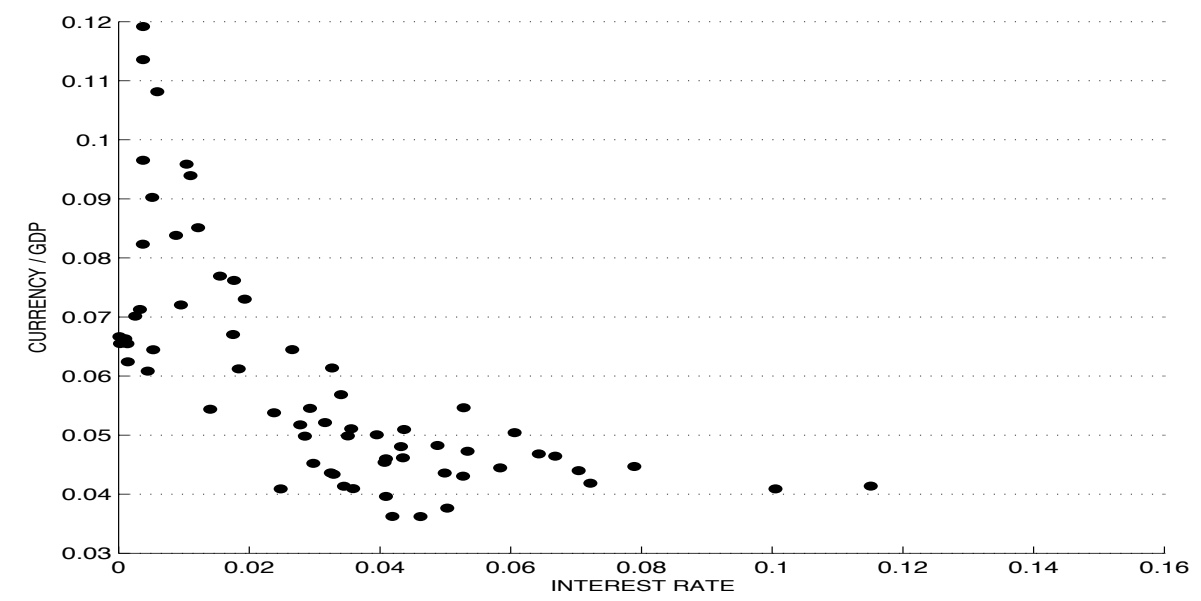

Figure 1c: Demand Deposits/GDP vs. Interest Rate (Three-Month T-Bill), 1915 - 1980

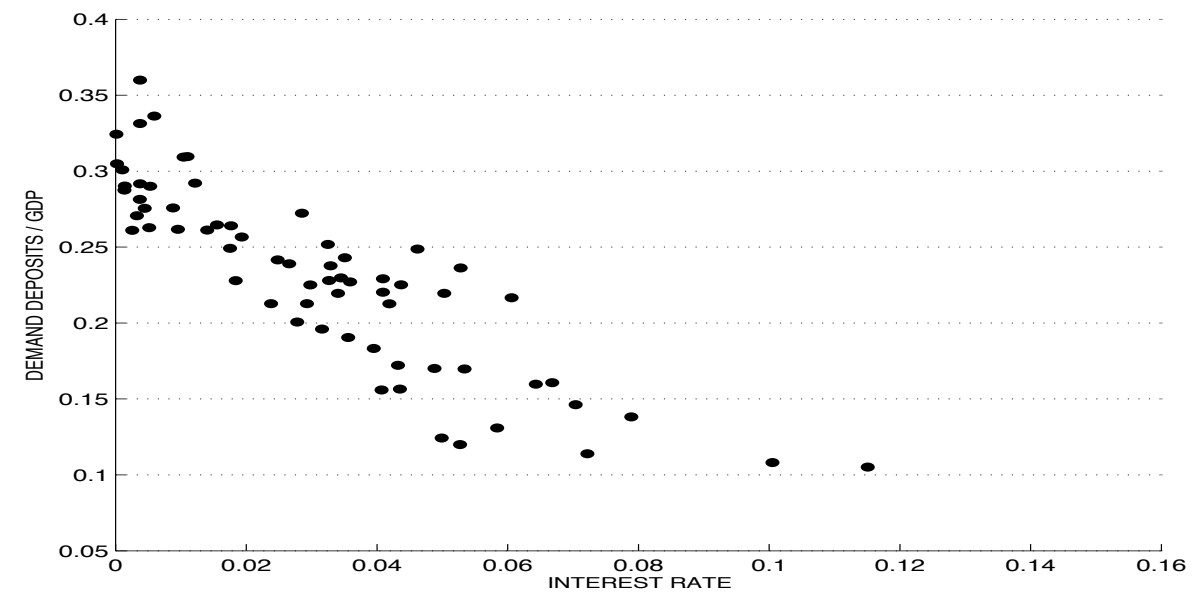


Figure 2a: M1/GDP vs. Interest Rate (Three-Month T-Bill), 1915 - 2012

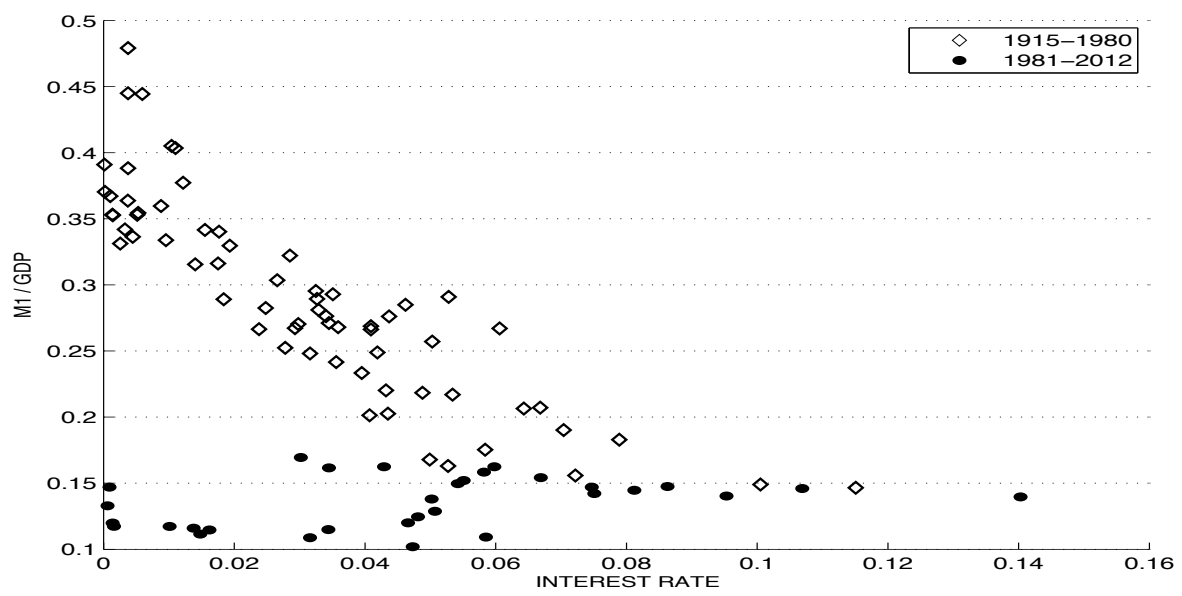

Figure 2b: Currency/GDP vs. Interest Rate (Three-Month T-Bill), 1915 - 2012

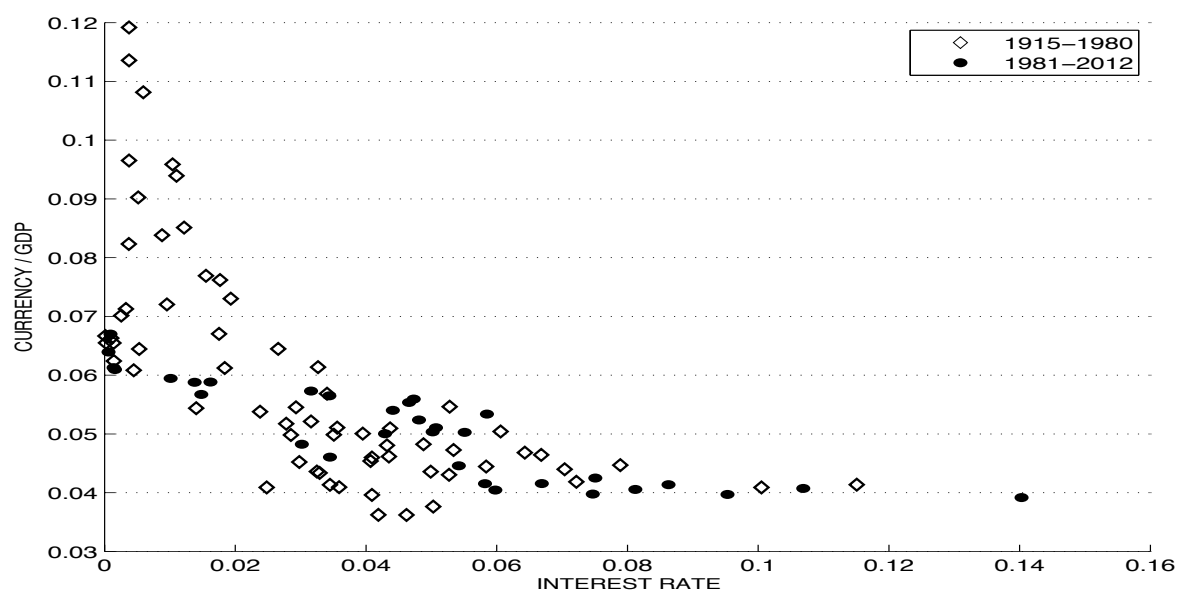

Figure 2c: Demand Deposits/GDP vs. Interest Rate (Three-Month T-Bill), 1915 - 2012

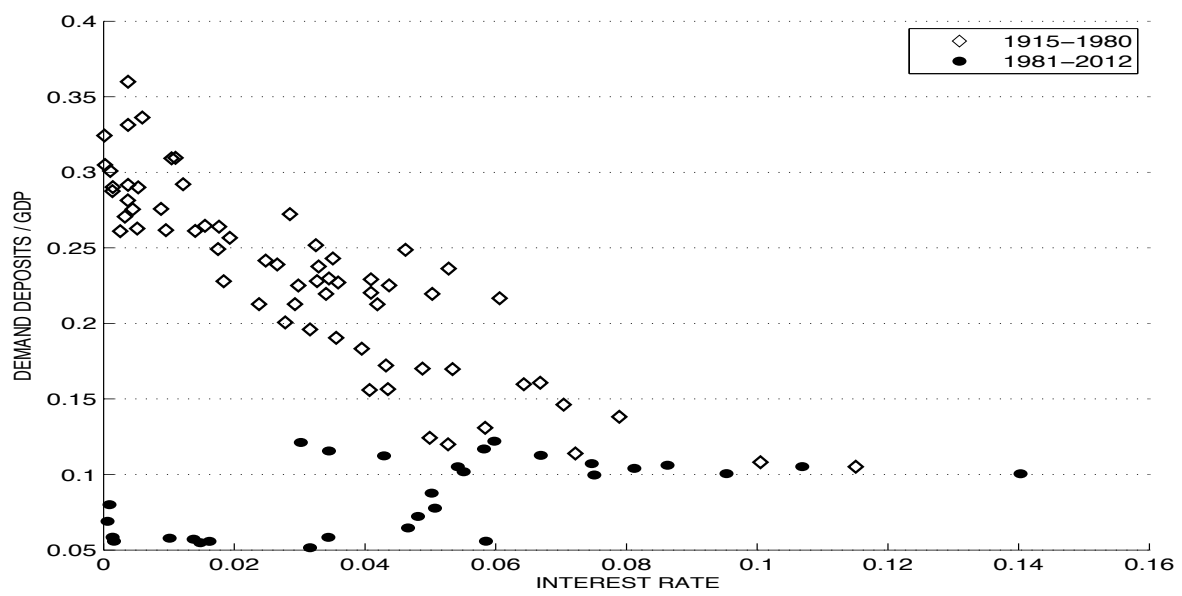


Figure 3: New M1 (M1+MMDAs) vs. Opportunity Cost, 1915 - 2012

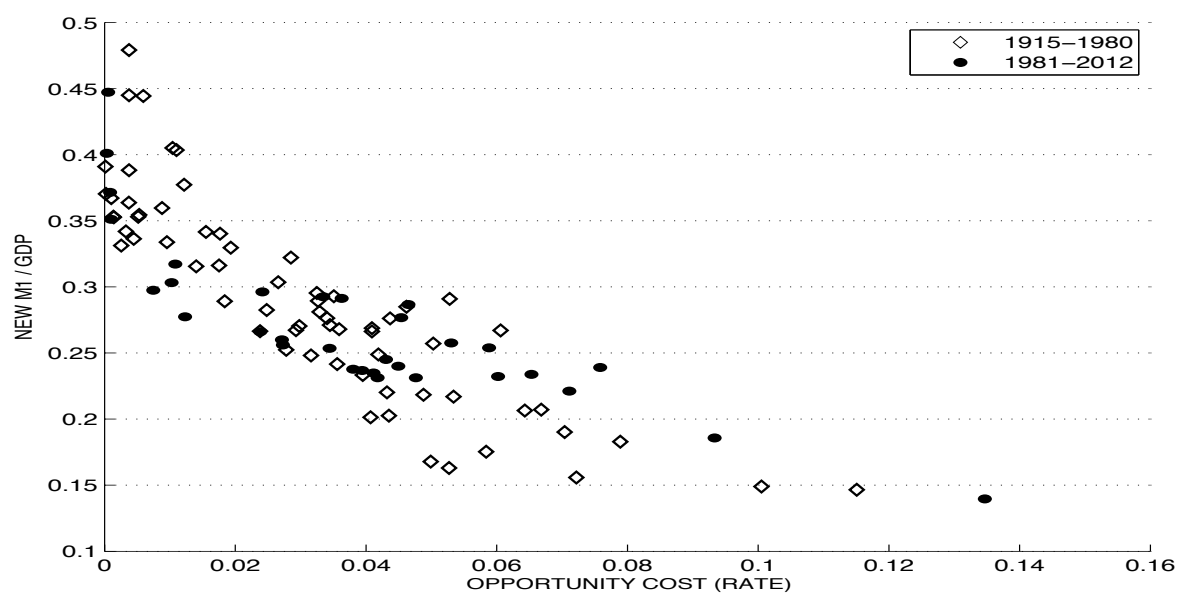

Figure 4a: The two functions that solve for $n$ and $\gamma$

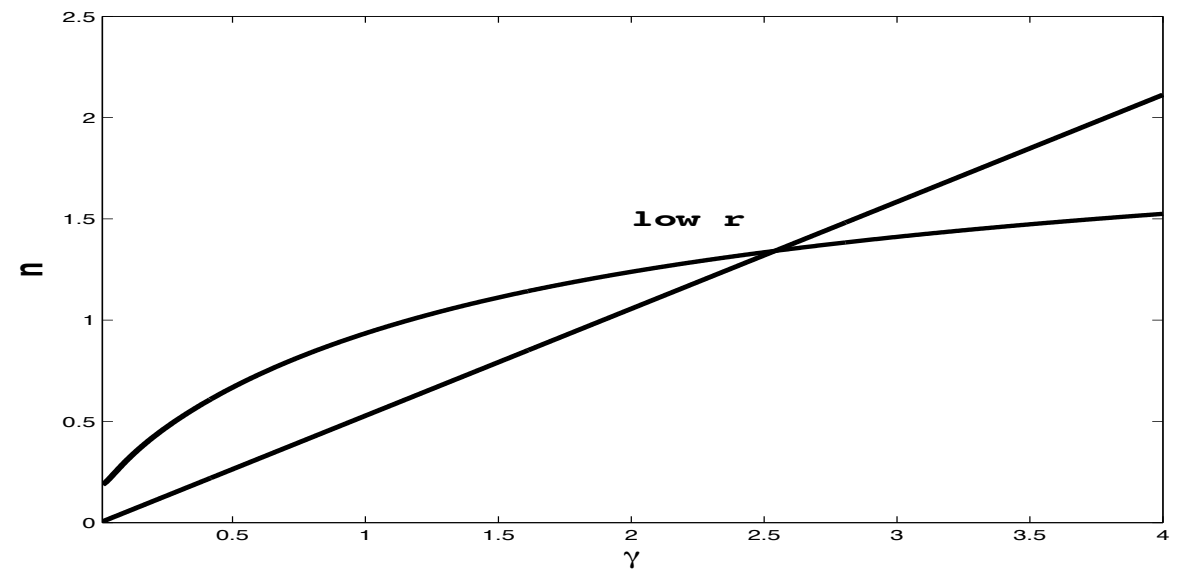

Figure 4b: Changes in solution as $r$ changes

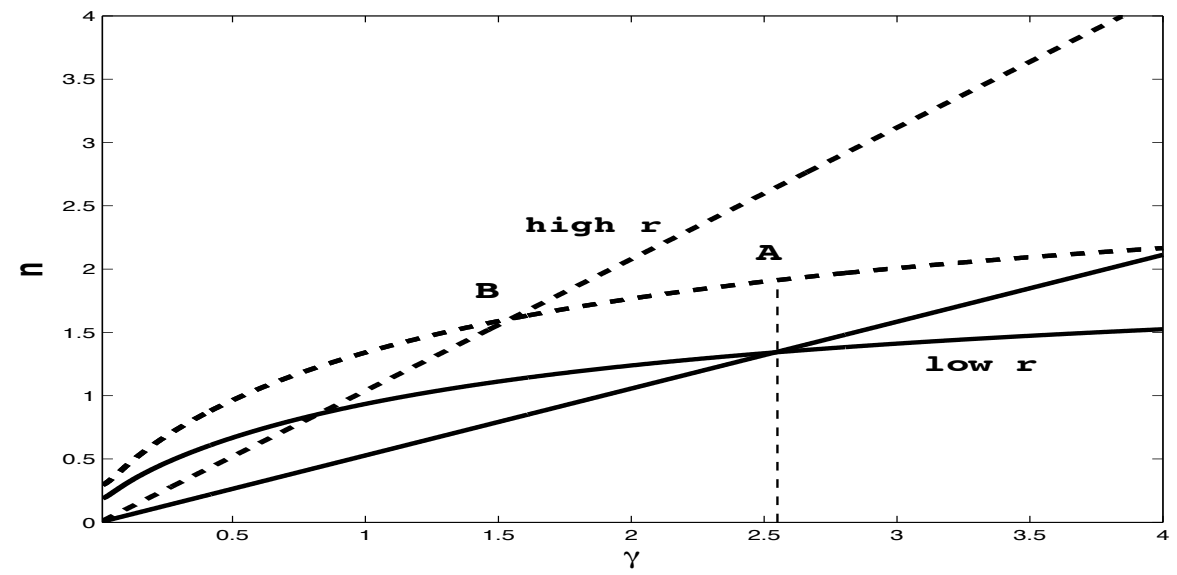


Figure 5a: Currency / Demand Deposits, 1984 - 2012

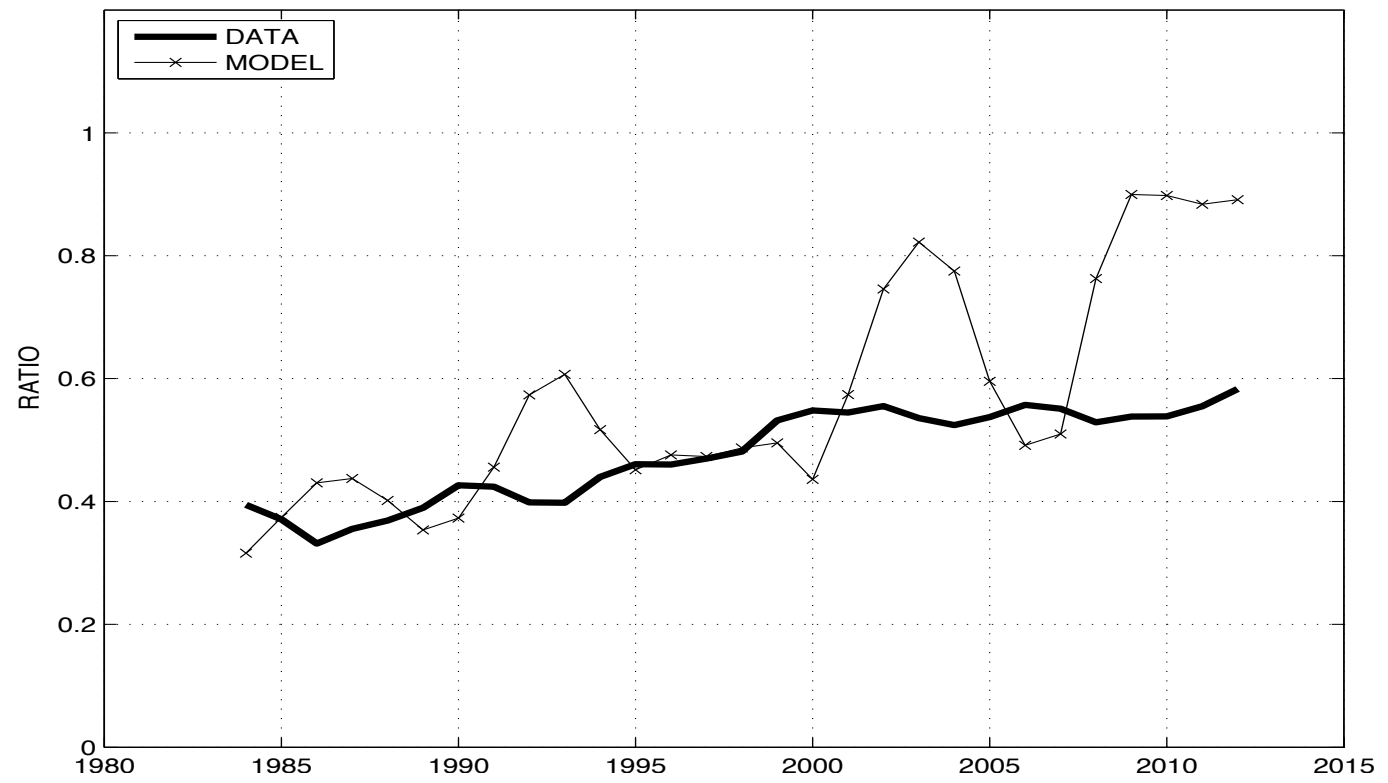

Figure 5b: Currency / Demand Deposits - trend component, 1984 - 2012

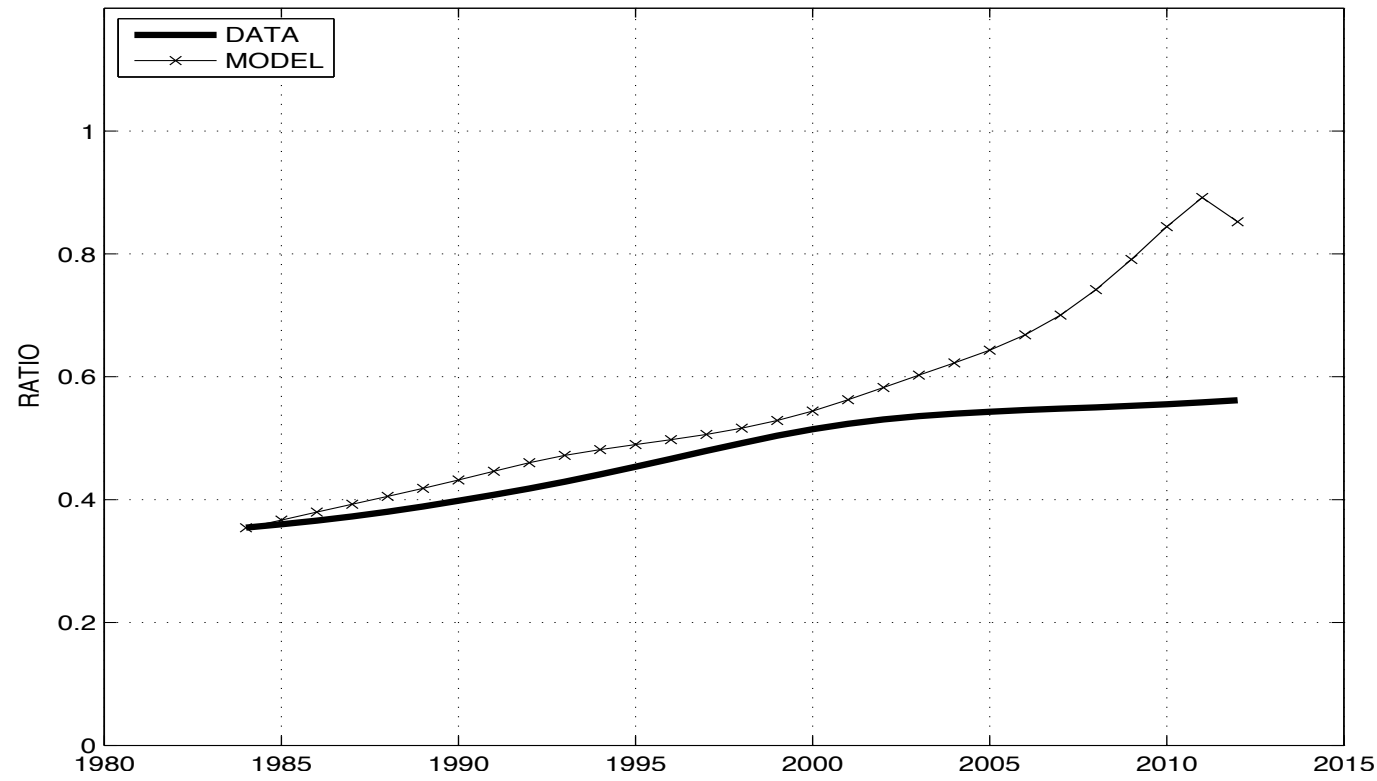


Figure 5c: Demand Deposits / (Demand Deposits+MMDAs), 1984 - 2012

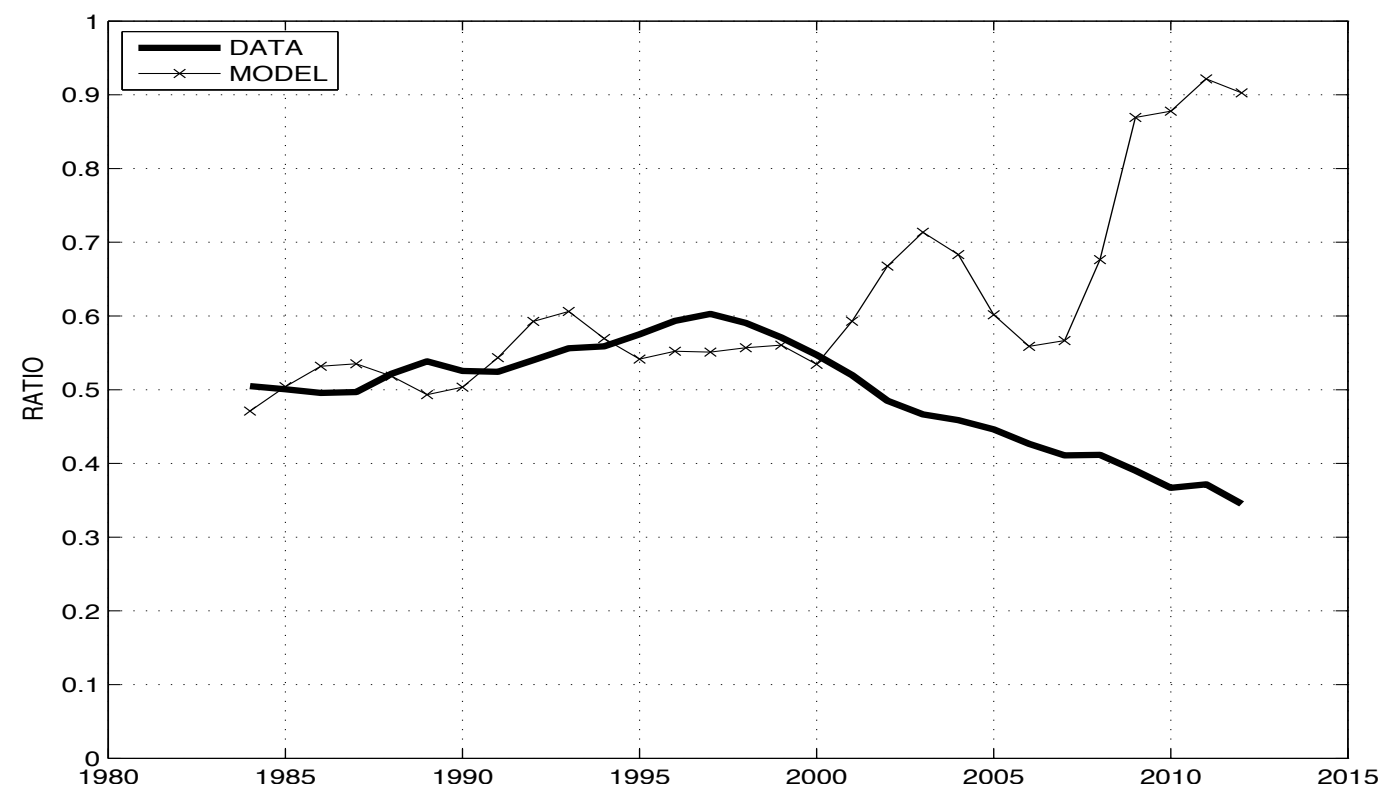

Figure 5d: Demand Deposits / (Demand Deposits+MMDAs) - trend component, 1984 - 2012

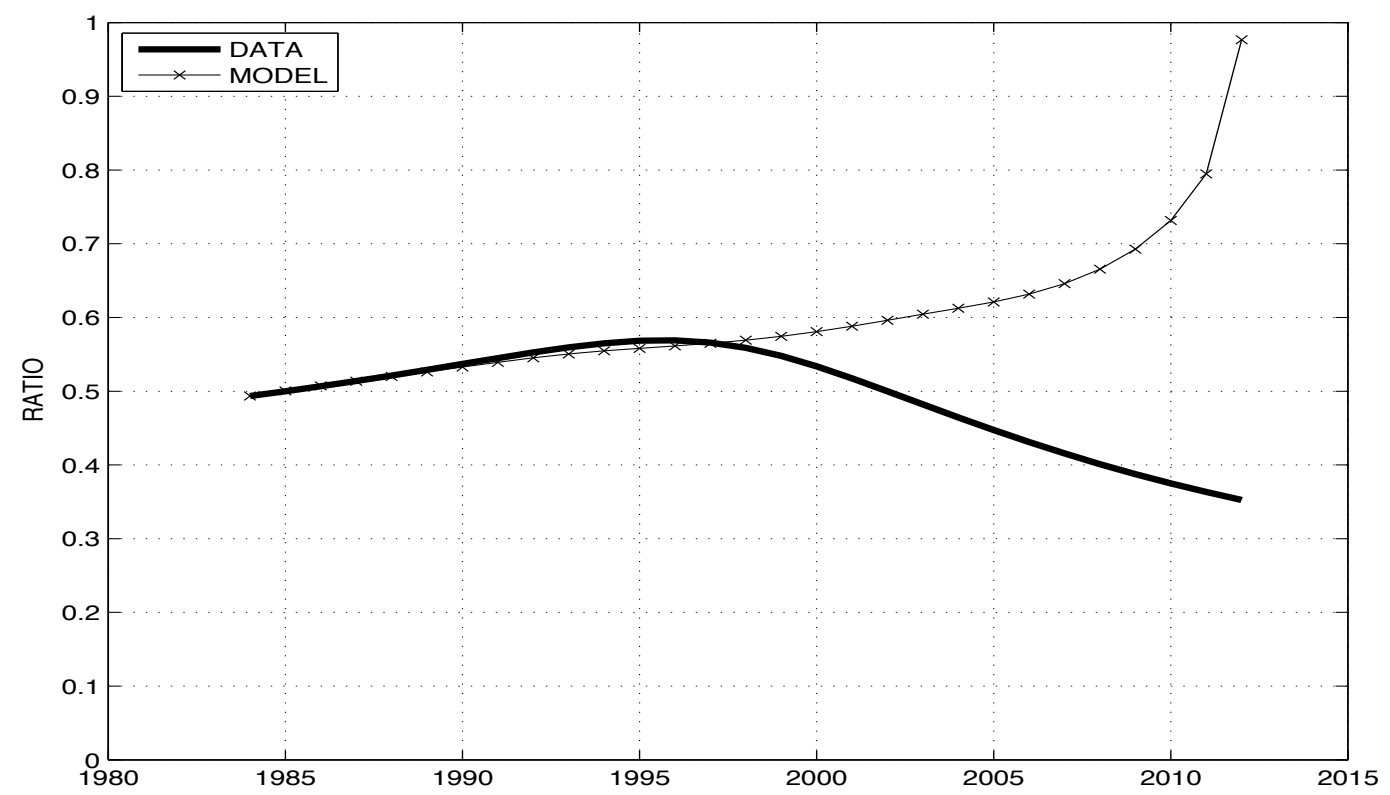


Figure 6: M1/GDP vs. Interest Rate (Three-Month T-Bill), 1915 - 1935 \& 1983 - 2012

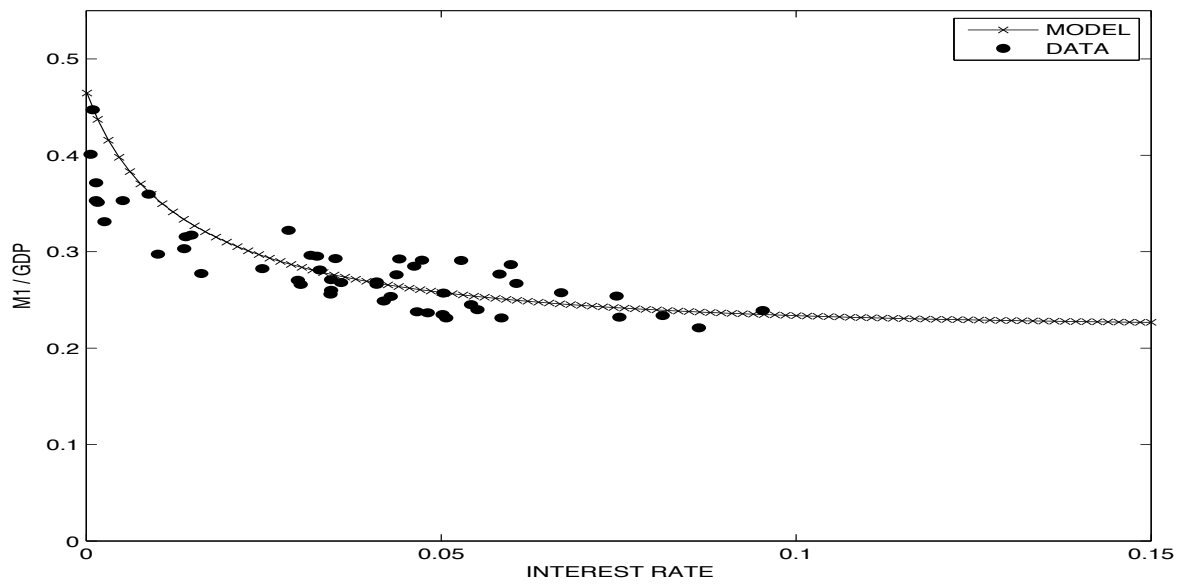

Figure 7a: Demand Deposits / (Demand Deposits+MMDAs) - trend component, 1984 - 2012

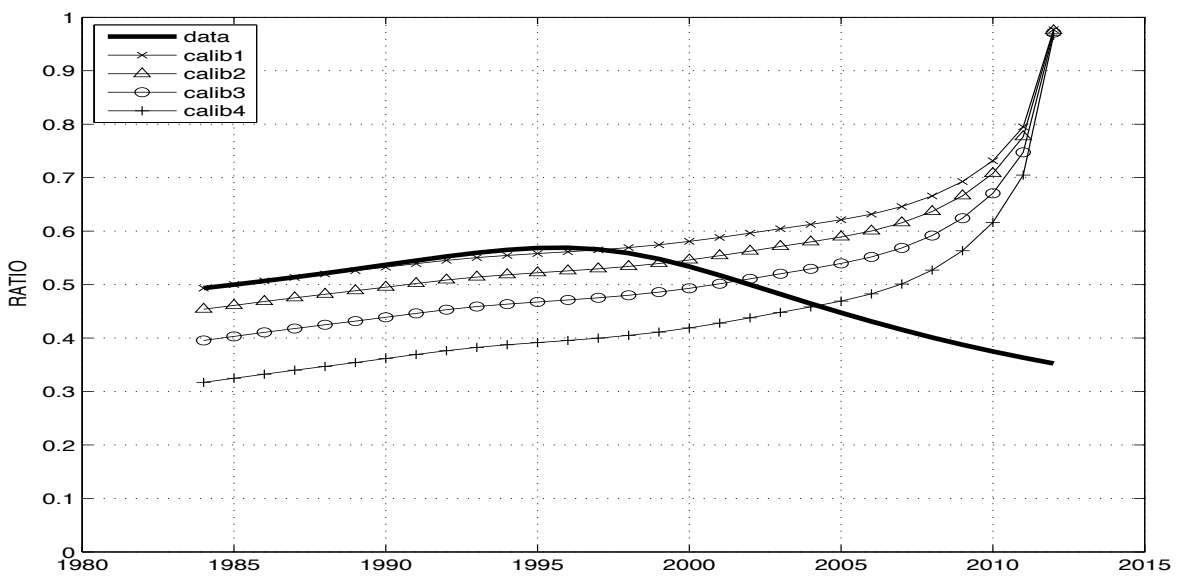

Figure 7b: M1/GDP vs. Interest Rate (Three-Month T-Bill), 1915 - 1935 \& $1983-2012$

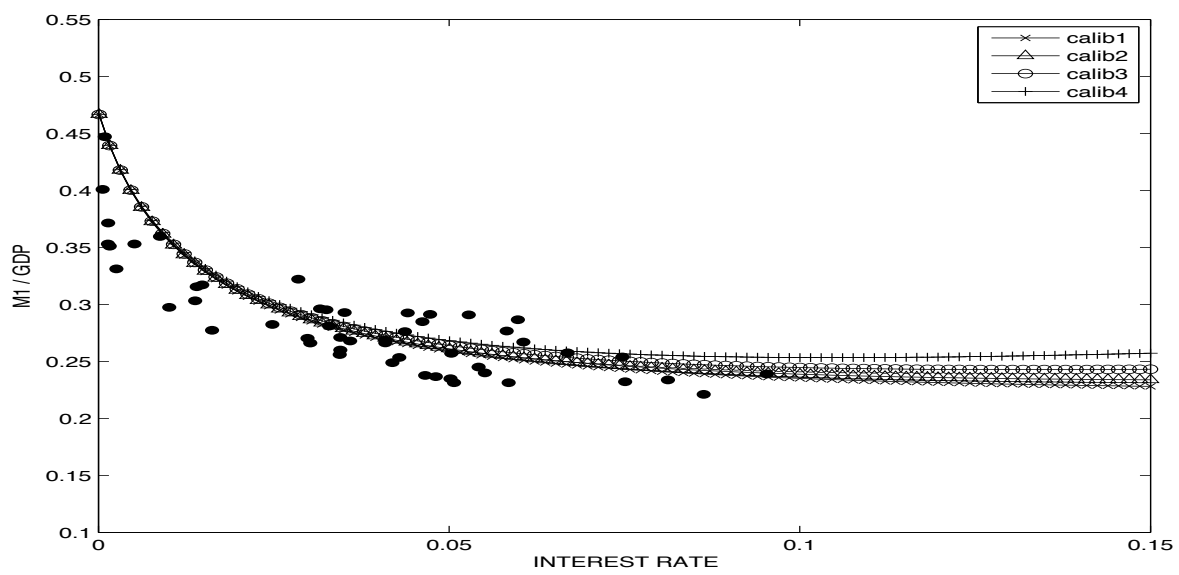


Figure 8a: M1/GDP vs. Interest Rate (Three-Month T-Bill), 1935 - 1982

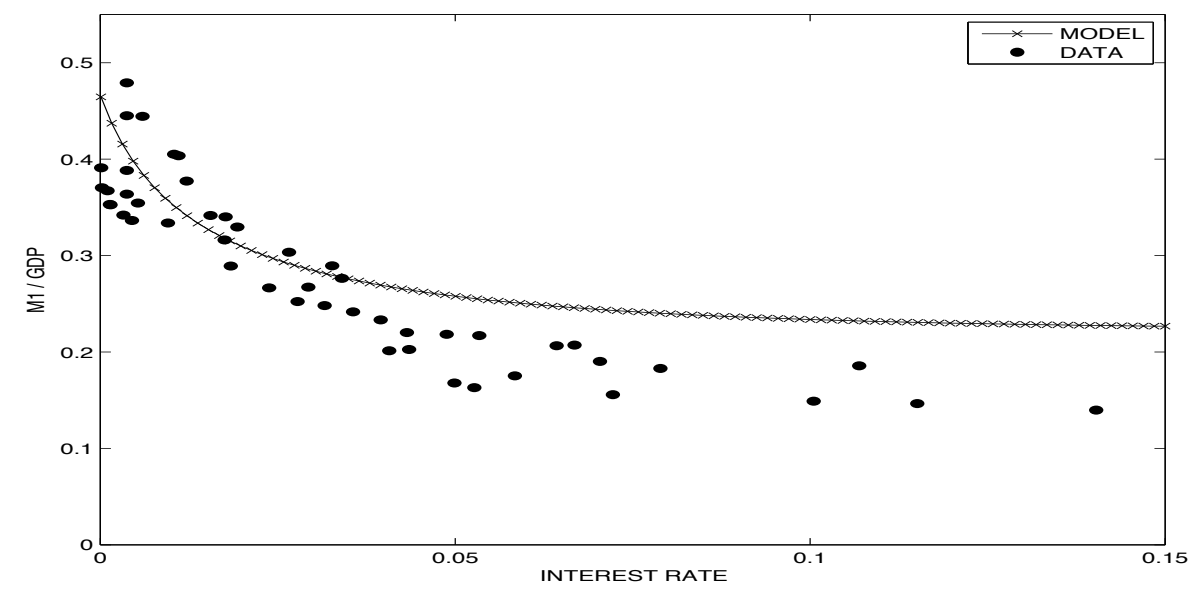

Figure 8b: M1/GDP vs. Interest Rate (Three-Month T-Bill), 1935 - 1982

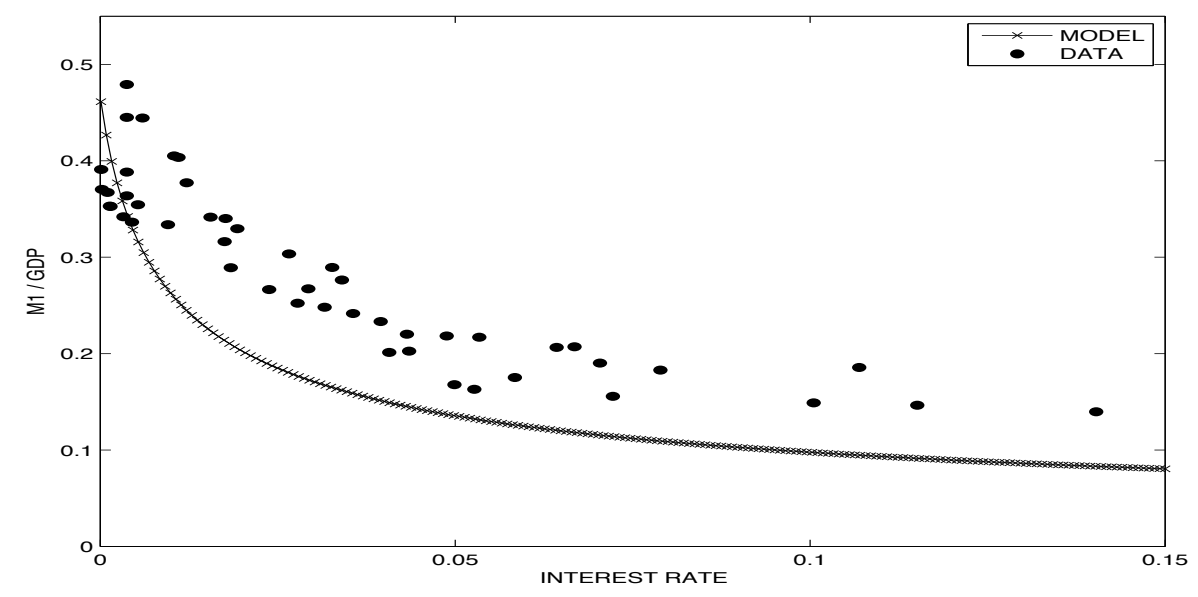

Figure 8c: Currency/New M1 (M1+MMDAs) vs. Interest Rate (Three-Month T-Bill), 1935 - 1982

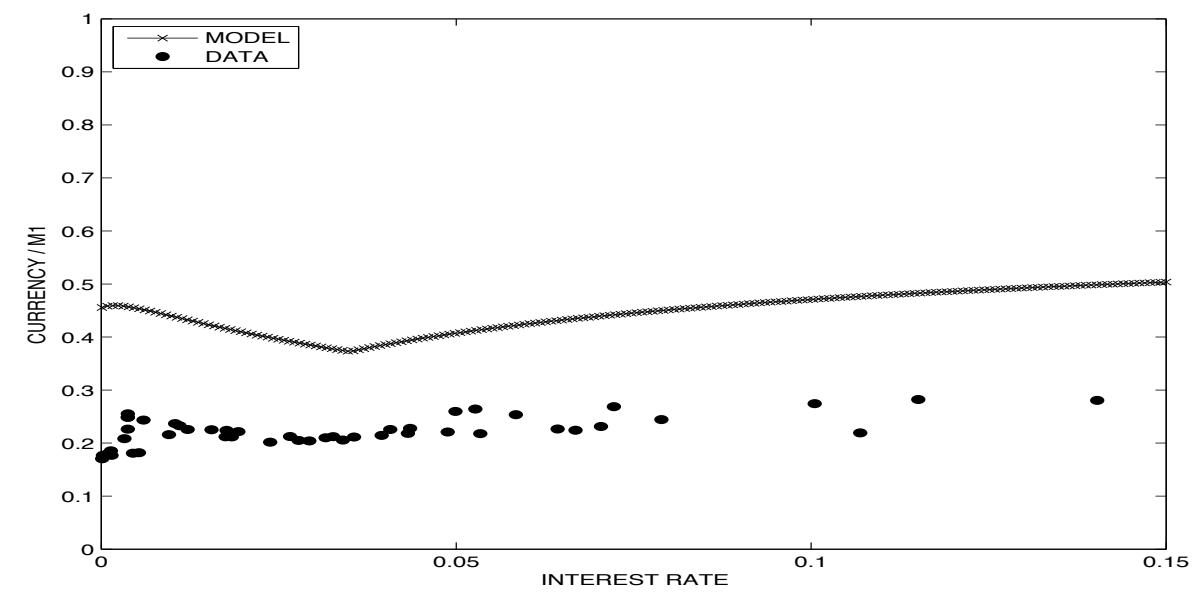

